\title{
Modelo de indicadores de calidad de las universidades
}

\section{Jesús M. de Miguel, Jordi Caïs y Elizabeth Vaquera}

¿Quién lee ahora a OrTEGay Gasset? No se lee ya su Misión de la Universidad, a pesar de que todavía sorprende por su modernidad '. Se publica casi al mismo tiempo que La rebelión de las masas, quizás su libro más leído en el mundo. ORTEGA. intuye que la universidad tiene tres funciones: docencia, investigación y compromiso. La universidad se dedica a preservar y avanzar el conocimiento. La docencia es su misión principal. Pero además tiene que ser «ciencia» en el sentido de realizar investigación, de inquirir sobre los problemas científicos. Cuanto más se avanza y más específico es un Departamento concreto dentro de una universidad, más problemas detecta y más extenso es su campo para la investigación. El drama en el siglo XXI es que una universidad ya no puede cubrir todas las ciencias, ni todos los problemas. Por lo tanto, tiene que definir prioridades y líneas de investigación. La Universidad siempre está entre la duda de si especializarse mucho o conservar la visión global del conocimiento. En tercer lugar, la Universidad supone compromiso, con la sociedad en la que está ubicada, con los problemas sociales que existen, los debates intelectuales y sociales que se producen. Una Universidad no puede quedar ajena a los sucesos importantes que ocurren en la sociedad, igual que no debe olvidar las polémicas más importantes. Max WEBER consideraba que la ciencia tiene que ser neutral al ejercitarla, pero que no puede serlo al elegir los temas sobre los que va a investigar. La calidad de una universidad debe, pues, tener en cuenta esas tres misiones: docencia, investigación y compromiso; así como su relación entre las tres. ORTEGA Y GASSET señala que el sistema universitario no puede ser diferente de la sociedad en que se integra. Es un principio sociológico básico, pero que se tiende a olvidar. Con sus propias palabras: «Esto nace de un error fundamental que es preciso arrancar de las cabezas y consiste en suponer que las naciones son grandes, porque su escuela —elemental, secundaria o superior- es buena. Esto es un residuo de la beatería "idealista" del siglo pasado [el xxx]. Atribuye a la escuela una fuerza creadora histórica que no tiene ni puede tener. Aquel siglo, para entusiasmarse y aun estimar hondamente algo, necesitaba exagerarlo, mitologizarlo. Ciertamente, cuando una nación es grande, es buena también su escuela. No hay nación grande si su escuela no es buena. Pero lo mismo debe decirse de su religión, de su política, de su economía y de mil cosas más. La fortaleza de una nación se produce íntegramente. Si un pueblo es políticamente vil, es vano esperar nada de la escuela más perfecta. Sólo cabe entonces la escuela de minorías, que vive aparte y contra el resto del país. Acaso un día los educados en ésta influyan en la vida total del país y al través de su totalidad consigan que la escuela nacional (y no la excepcional) sea buena.» (1930: 19). El análisis de la calidad de las universidades españolas tiene que realizarse, en el contexto nacional de unas con otras, antes incluso que la comparación con las mejores universidades investigadoras del mundo. Para ese caso se necesitaría otra vara de medir, y quizás otros indicadores. En ello estamos ya trabajando.

Téngase en cuenta tan sólo el ejemplo de las bibliotecas universitarias. La media de las universidades españolas es de 400.000 ejemplares por biblioteca. Éste es un indicador de la pobreza mental de nuestras universidades, como diría el propio ORTEGA Y GASSET. El que haya universidades en España con 50.000 libros es impensable en una sociedad avanzada. Apenas la Universidad Complutense de Madrid con 2,1 millones de volúmenes, o la Universidad de Barcelona con 1,5 millones, puede decirse que tienen una biblioteca universitaria aceptable. Pero en un análisis de calidad tiene que asumirse que los niveles 
de biblioteca son bajos, mucho menores que lo que sería si se quisiera comparar nuestras universidades con la Ivy League, Oxbridge, algunas alemanas, o la Universidad de Tokio. El análisis que aquí se presenta vale solamente para la realidad española; y en ello reside su utilidad. Los indicadores estudiados suponen una buena aproximación a la calidad global de las universidades. Miden las tres misiones de la universidad. El conocimiento - sobre todo el conocimiento aplicado- debe medirse por carreras, o mejor aún por Departamentos universitarios. Pero esos datos actualmente no están disponibles. Es posible que en los próximos años se generen esas estadísticas. Uno de los objetivos principales de la mejora de la calidad universitaria es producir datos sobre la propia organización. Ése debe ser un objetivo urgente en la primera década del siglo XxI.

\section{Indicadores fundamentales}

El presente estudio sobre la calidad universitaria parte de 71 indicadores básicos, y una docena adicional de indicadores especificos. Se dividen operativamente en seis factores: a) de desarrollo provincial, b) estructura organizativa, c) recursos humanos y materiales, d) feminización, e) doctorado, y $\mathrm{f}$ productividad. En cada factor hay aproximadamente una docena de indicadores que se han analizado y estudiado sus relaciones internas. Es importante elegir indicadores fiables y centrales, pues de ellos depende luego el cálculo general de calidad. Por eso el estudio detallado de los indicadores en cada factor es esencial. De cada factor el análisis estadístico y correlacional permite elegir un indicador fundamental que: funciona mejor, mide un espectro extenso de conceptos dentro del propio factor, y varía bastante (pero no excesivamente) entre las universidades. En el caso de recursos se han elegido dos indicadores, uno para recursos humanos (de profesorado) y otro para recursos materiales (de libros y bibliotecas). Se proponen indicadores fundamentales con datos para todas las universidades, de tal forma que puedan ser comparadas. A lo largo del estudio se observa que las universidades privadas (sobre todo, las nuevas) carecen a menudo de datos, o esos datos no son fiables del todo, dada la juventud y tamaño pequeño de las universidades. Los indicadores elegidos para medir la calidad global de las universidades son los seis siguientes (en el análisis aparecen identificados con un asterisco delante):

FET Centros con carreras largas (en números absolutos).

PRO Tasa de profesorado (según el tamaño de la universidad).

LBE Libros de biblioteca (por estudiante).

MPR Mujeres profesoras (\% del total de profesorado).

TDE Títulos de doctor concedidos (por cada mil estudiantes).
ETC Estudiantes que terminan la carrera en los años justos (en $\%$ de los/as que empezaron).

Estos indicadores tienen como media de toda España (no la media de las universidades, sino del indicador en toda Espana) las siguientes cantidades medias por universidad:

FET 10 centros de carreras largas (Facultades y ETS).

PRO 5,4 profesores por cien estudiantes (varones y mujeres).

LBE 14 libros de biblioteca por cada estudiante.

MPR 33 mujeres entre el profesorado en porcentajes.

TDE 3,8 títulos de doctor concedidos ese año por cada mil estudiantes.

ETC 58 estudiantes que terminan la carrera en los años justos, en porcentajes.

La discusión de los seis factores (con los 71 indicadores) y sus relaciones demuestran que estos seis indicadores son los más válidos y fiables para medir la calidad de la Universidad. El primer indicador (FET) mide la universalidad o extensión de áreas de conocimiento de una universidad. Se considera que una universidad de calidad no es una organización que se especializa en una o dos carreras, sino que realiza docencia e investigación básica en un abanico de especialidades. No debe faltar una representación de las ciencias incluyendo las biomédicas, las bumanidades o letras (incluyendo filologías), las ciencias lla. madas sociales (incluyendo jurídicas y económicas), e incluso ingenierías o carreras más tecnológicas. Estos cuatro campos extensos de estudios e investigación cubren el arco iris del conocimiento humano en la sociedad contemporánea. Pocas universidades cubren toda esta variedad, pero es un ideal que la universitas cubra bastantes saberes. La media es de 10 centros «superiores», lo que es suficiente para cubrir saberes distintos pero no para cubrir todos los más importantes. La variabilidad es considerable, pues va desde 1 a 28 centros «superiores» (es decir, de carreras largas) en universidades extremas. La definición de «centro» no está clara, pues antes centro era igual a carrera, pero en la actualidad un centro puede incluir varias carreras ${ }^{2}$. Las universidades que tienen pocos centros a menudo es porque todavía los están creando, estando así en expansión. Hay que esperar al menos dos décadas para observar una estructura algo más cristalizada. El número de centros que contienen carreras largas puede discutirse como indicador de calidad, aunque se reconoce que para que una universidad sea considerada como «buena», «de calidad» o de «prestigio» requiere tener más de una docena de carreras diferentes. Otros añadirían que no le falten carreras básicas, emblemáticas, como Derecho, Medicina, Economía, Filologías, Arquitectura, etc. Pero esta lista sería más discutible. La media de 10 es tan baja que en el cálculo global de la calidad este indicador (FET) debería multiplicarse por una constante, quizás por dos (es decir, que el indicador contase como doble). 
El segundo indicador PRO es obvio para evaluar la calidad de las universidades. Mide la cantidad de profesores/as que tiene la universidad, en relación con su tamaño, medido por el número total de estudiantes de todo tipo. La media es $5 \%$, es decir, un profesor/a por cada 19 ó 20 estudiantes. La variabilidad es grande, pues las universidades españolas van de 1 a 16 en la tasa de profesorado. Se podría discutir que la calidad depende de lo que enseñe e investigue ese profesorado, su edad, proporción de doctores, dedicación, nivel docente, experiencia, salario, nivel administrativo, etc. Habría que cualificar muchas cosas en este indicador simple de tasa de profesorado, pero de por sí es un indicador esencial, que marca bien las diferencias entre universidades. Es también el más utilizado en el resto del mundo para medir la excelencia universitaria. Es el indicador más ambicioso de capital humano, aunque también la tasa de catedráticos (CAT, catedráticos por mil estudiantes) es un indicador interesante. CAT y PRO correlacionan 0,31, lo que sugiere que CAT es un indicador más especializado. El profesorado de todo tipo es uno de los recursos más importantes en una universidad, si no el esencial. PRO es uno de los indicadores centrales en la calidad, y, por lo tanto, su número debe multiplicarse por una constante elevada, teniendo en cuenta que la tasa al medirse por cien estudiantes es bastante baja $(5,4)$. Lo lógico sería medirlo como una tasa por mil estudiantes (54).

El tercer indicador es LBE, es decir, el número de libros de biblioteca por cada estudiante. Primero se pensó que el indicador mejor era el número absoluto de libros de biblioteca en una universidad (NLB). Pero aunque las diferencias son grandes, las universidades más recientes obviamente no han podido acumular en pocos años (a veces menos de un lustro) un fondo de biblioteca grande. Además, no tienen muchos estudiantes, ni carreras distintas, por lo que la cantidad absoluta de libros no parece el indicador ideal. Se pensó, pues, en LBE, que correlaciona mejor con otros recursos, y que pone en relación las bibliotecas con el tamaño de la universidad. Oscila entre 2 y 56 libros por estudiante, lo que supone una variabilidad adecuada. Hay que tener en cuenta que las universidades más tecnológicas no requieren tantos libros, sino más laboratorios u otro tipo de equipamiento. Por eso es un indicador que debe tomarse con cierta precaución, pues favorece a las universidades con Facultades y desfavorece a las universidades politécnicas o tecnológicas. Pero también se asume que la especialización en «universidad tecnológica» no es un factor de calidad universitaria, pues se aparta del objetivo de universitas o de variedad de saberes (docencia e investigación). La media española es 14 libros por estudiante, lo que es muy bajo a nivel internacional. La universidad que más libros tiene es la Complutense con 2,1 millones, seguida de Barcelona con 1,5 millones. La tercera, Sevilla, no llega a un millón de volúmenes. Puede decirse que apenas dos o tres de las 54 universidades españolas tienen libros suficientes para ser consideradas como universi- dades investigadoras o centros de excelencia. Este indicador, con media de 14, debería quizás contar como doble aunque eso desfavorezca ligeramente a las universidades politécnicas.

El cuarto indicador MPR es el más debatible. Los tres autores del presente estudio consideramos que la variable «feminización de la universidad» es un factor altamente positivo, incluso de calidad de la universidad. Una universidad a la que se permite acceder en igualdad de condiciones a estudiantas y profesoras es claramente una universidad «mejor», que no discrimina, y que no desaprovecha recursos que existen en el país. Hay ya más estudiantes-mujeres (53\%) en la universidad que varones, por lo que puede afirmarse que la universidad española - por primera vez en la historia - no discrimina por género a los estudiantes. Por eso las variables MEN (proporción de mujeres entre estudiantes nuevos) y MES (proporción de mujeres entre el total de estudiantes) ya no pueden considerarse globalmente como indicadores «de calidad», «diversidad» o de «no-discriminación». Las mujeres terminan bastante más la carrera que los varones (en el indicador MEC hay un 58\% de mujeres). Por eso el mejor indicador del proceso de feminización es MPR, es decir, el porcentaje de mujeres entre el profesorado de todo tipo, pues la media es todavía sólo $33 \%$. Hay, pues, todavía posibilidades de progreso en ese indicador. Si llegase al $50 \%$ con una buena distribución por universidades, seria ya innecesario incluir el factor de feminización en un índice global de calidad de la universidad. En la actualidad la media es $33 \%$, pero varía entre $18 \%$ y $45 \%$, lo que sugiere que además es un indicador bastante válido para medir diferencias entre universidades. También se podría incluir la proporción de catedráticas (indicador MCA, 14\% de mujeres), pero hay universidades privadas que no siguen ese sistema de profesorado. Dado que MPR es un indicador en realidad de diversidad (de no-discriminación contra la mujer), quizás no deba contar mucho en la fórmula final del índice de calidad; es decir, incluyéndolo sin factor de multiplicación, o incluso contándolo sólo como la mitad.

El quinto indicador TDE es también central. Partimos de que la misión de la universidad es triple: docencia, investigación y compromiso. Los datos oficiales disponibles permiten medir recursos, pero poco la investigación, y menos aún el compromiso social. El indicador TDE tiene en cuenta los títulos de doctor que concede la universidad al año, en relación con el tamaño de la universidad (tasas por mil estudiantes de todo tipo). Es una cantidad baja - una media de 3,7 títulos de doctor-, lo que indica otro de los problemas fundamentales de las 54 universidades españolas para ser consideradas como universidades de calidad. Las diferencias son grandes, entre casi cero y 15 títulos de doctor por millar de estudiantes. Una universidad investigadora debería llegar al menos a seis títulos de doctor por mil estudiantes al año, pero eso supondría que en España las universidades investigadoras se podrían contar con los dedos 
de una mano: Navarra, Autónoma de Madrid, Autónoma de Barcelona, Barcelona, y Complutense. Es, pues, un indicador que simbólicamente hay que multiplicarlo por un factor alto (por lo menos 10 o incluso 15), pues es un valor absoluto bajo, pero que diferencia bien la calidad de la universidad.

El sexto indicador es ETC. Mide - de forma lo más aproximada que podemos con los datos existentes - la proporción de estudiantes que terminan la carrera en los años justos. Es un indicador difícil de calcular bien, pues los datos son a veces solapables, y otras veces incompletos. Pero la tendencia general es bastante válida. Se presenta en porcentajes, contabilizando los/as estudiantes que terminan los estudios en 1996, y comparando su número con los que empezaron tres o cinco años antes, según las carreras. Operativamente se ha supuesto tres años para Escuelas Universitarias (es decir, diplomado o ingeniero-técnico) y cinco años para Facultades o para Escuelas Técnicas Superiores (es decir, el título de licenciado, ingeniero, arquitecto). La media para todas las carreras y toda España es $59 \%$. Este dato supone que en el conjunto de todas las universidades españolas, públicas y privadas, hay aproximadamente la mitad de estudiantes que terminan la carrera en los años justos. Dado que hay carreras de primer ciclo que dan origen a segundos ciclos, repetidores, personas matriculadas en más de una carrera, defectos en los datos enviados por cada universidad en años distintos, etc., los datos no son totalmente fiables. Hay estudiantes que empiezan la carrera en una universidad y la terminan en otra. Algunos estudiantes no terminan nunca una carrera y se matriculan en otra. Hay estudiantes que mueren durante la carrera. Algunos se van a vivir al extranjero. Todas estas pequeñas excepciones son imposibles de tener en cuenta. Además, no es un estudio de cohortes, con nombres y apellidos de los/as estudiantes. No se puede garantizar que sean las mismas personas. Los problemas del índice de productividad deberían analizarse con más detalle. Es un índice importante, pues mide la productividad de cada universidad y el éxito en conseguir que sus estudiantes terminen la carrera en los años que están previstos. Que las personas suspendan, o que nunca terminen la carrera - una vez que pasaron la selectividad general y la específica de esa carrera-, es un indicador de mala calidad de una institución y de baja utilización de sus recursos. Las diferencias son de diez veces entre universidades extremas (UNED y Navarra). ETC es un indicador extraordinariamente interesante para medir la calidad de una institución. Pero dado que la única forma de medirlo introduce algunos errores, no debe ponderarse más que su propio valor, que de media es ya bastante alto (59).

La Tabla 1 presenta los valores de estos seis indicadores de calidad, para el año 1997, junto con tres de referencia que son útiles para interpretarlos: PIB que mide el nivel de riqueza provincial (medido por el producto interior bruto per capita), ANT o antigüedad de la universidad medida en años, y DPP que indica si la universidad es pública o privada (adjudicando valores operativos de uno si es pública, y de cero si es privada). Salvo en doctorado y en productividad hay datos para las 54 universidades. No se aplican todos en cuatro universidades privadas (de las diez) para TDE y ETC. La distribución por universidades muestra los seis factores con sus indicadores respectivos. De los indicadores fundamentales los cuatro primeros (FET, PRO, LBE y MPR) se refieren a 1997, y TDE y ETC a 1996. Esto depende de los datos oficiales sobre terminación de carrera/doctorado, que se elaboran con un poco más de retraso.

La tabla incluye la media de la nota de selectividad de todos los estudiantes que ingresan ese año en la universidad, como SEL. La media de España es baja: 5,65 sobre una escala que va desde cero a diez. Realmente no hay grandes diferencias entre universidades. Sorprendentemente, la universidad con nota media más alta es Las Palmas con 7,07 a pesar de ser una universidad con indicadores de calidad bajos en el contexto español. La media más baja es UNED con 5,00. Para calcular la excelencia de las universidades españolas se podría haber utilizado, únicamente, este indicador, pues señala supuestamente la calidad atribuida por los/as estudiantes a cada universidad. Sin embargo, esta media de notas de selectividad - que es media realmente de estudiantes, no de las carreras - no funciona de forma adecuada. Cantabria tiene notas muy altas. Las politécnicas tienen las notas más altas, pues sus carreras son más competitivas. Está claro que lo que explica esa nota alta es el carácter politécnico de las universidades. La siguiente es Pompeu Fabra, que realmente sí es una universidad de excelencia, aunque la media es apenas 6,02. Llama la atención las notas tan bajas que supone la entrada a la universidad española (apenas un aprobado raspado), y las muy pequeñas diferencias si no se tienen en cuenta las universidades mayoritariamente politécnicas: entre 5,00 y 6,02. Con este indicador no es posible medir la calidad de las universidades españolas, aunque correlaciona positivamente con todos los otros indicadores, a excepción del de mujeres-profesoras (MPR).

La Tabla 2 incluye los seis indicadores de calidad especificando sus estadísticos descriptivos como el máximo/mínimo, media, mediana, moda, desviación estándar, etc. También se incluyen los coeficientes de correlación entre los seis indicadores, controlando por PIB (riqueza provincial), ANT (antigüedad), DPP (pública/privada) y SEL (nota media de selectividad). Así se observa la variación de los indicadores: FET 28 veces, PRO 16 veces, LBE 28 veces, MPR 3 veces, TDE 30 veces, y ETC 9 veces. Lo que más varía es la producción de títulos de doctor, lo que es interesante en la definición de la calidad de las universidades. Lo que menos varía es MPR -proporción de mujeres profesoras-, lo que sugiere que en cuanto a diversidad por género las universidades españolas tien- 


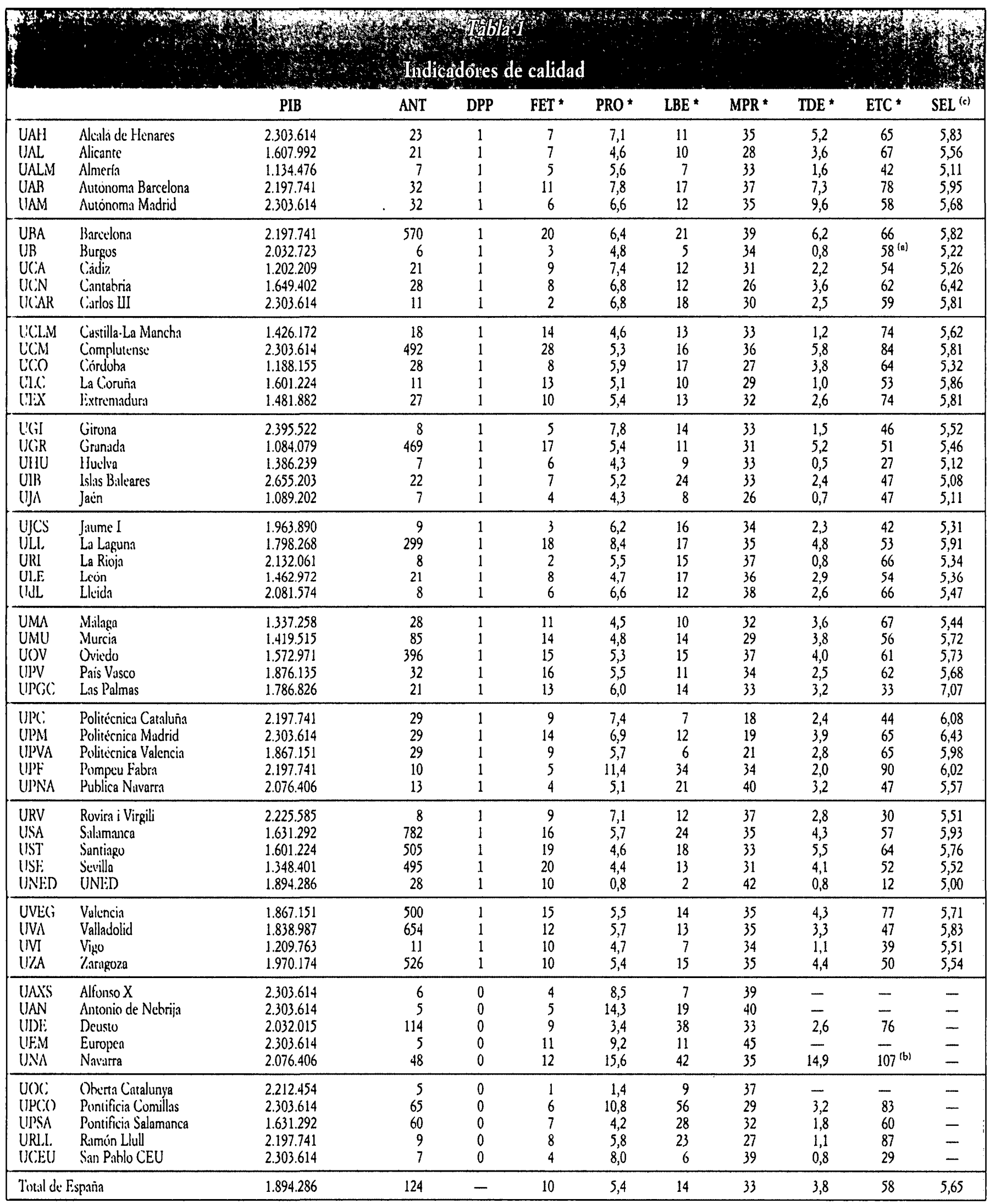

Notas: Los indicadores de calidad son los seis con asterisco.

(a) En Burgos no hay dato, se incluye indicativamente la media de las universidades.

(b) Según las estndisticas oficiales de la universidad.

(e) El indicador SEL es la nota media de selectividad de los/as estudiantes en las diversas universidades públicas. 


\begin{tabular}{|c|c|c|c|c|c|c|c|c|c|c|}
\hline \multicolumn{11}{|c|}{$\begin{array}{c}\text { Tabla } 2 \\
\text { Estadísticos y correlaciones de los indicadores de calidad }\end{array}$} \\
\hline Estadísticos descriptivos & PIB & ANT & DPP & FET * & PRO * & LBE * & MPR * & $\mathrm{TDE}^{*}$ & ETC * & SEL \\
\hline Media & 1.868 .026 & 124 & 1 & $\cdot 10$ & 6 & 16 & 33 & 3 & 58 & 6 \\
\hline Error estándar & 55.836 & 28 & 0 & 1 & 0 & 1 & 1 & 0 & 3 & 0 \\
\hline Mediana & 1.929 .088 & 25 & 1 & 9 & 6 & 13 & 34 & 3 & 59 & 6 \\
\hline Moda & 2.303 .614 & 21 & 1 & 9 & $\# N / A$ & \#N/A & $\# N / A$ & $\# N / A$ & $\# N / A$ & 6 \\
\hline Desviación estándar & 410.306 & 209 & 0 & 5 & 3 & 10 & $\begin{array}{r}\pi \sin \\
5\end{array}$ & $\begin{array}{c}\pi+\pi / n \\
2\end{array}$ & $\begin{array}{r}\pi N / \Omega \\
18\end{array}$ & 0 \\
\hline Varianza & 168.350 .826 .7746 & 43.672 & 0 & 30 & 6 & 91 & 27 & 6 & 314 & 0 \\
\hline Curtosis & -1 & 2 & 1 & 1 & 5 & 6 & 2 & 9 & 1 & 3 \\
\hline Asimetría & 0 & 2 & -2 & $i$ & 2 & 2 & -1 & 2 & 0 & 1 \\
\hline Rango & 1.571 .124 & 777 & $i$ & 27. & 15 & 54 & 27 & 14 & 96 & 2 \\
\hline Mínimo & 1.084 .079 & 5 & 0 & 1 & 1 & 2 & 18 & 0 & 12 & 5 \\
\hline Máximo & 2.655 .203 & 782 & 1 & 28 & 16 & 56 & 45 & 15 & 107 & 7 \\
\hline Sumatorio & 100.873 .382 & 6.690 & 44 & 525 & 336 & 838 & 1.791 & 167 & 2.859 & 249 \\
\hline $\mathrm{N}$ & 54 & 54 & 54 & 54 & 54 & 54 & 54 & 50 & 49 & 44 \\
\hline Confianza (95\%) & 111.992 & 57 & 0 & 1 & 1 & 3 & 1 & 1 & 5 & 0 \\
\hline Correlaciones & PIB & ANT & DPP & FET * & PRO * & LBE * & MPR * & TDE * & ETC* & \\
\hline ANT & $-0,14$ & - & - & - & - & - & - & - & - & \\
\hline DPP & $\begin{array}{r}0,17 \\
-0,35\end{array}$ & 0,21 & - & - & - & - & - & - & - & \\
\hline FET * & $-0,22$ & 0,68 & 0,27 & - & - & - & - & - & - & \\
\hline PRO* & 0,38 & $-0,13$ & $-0,36$ & $-0,09$ & - & - & - & - & - & \\
\hline $\mathrm{LBE}^{*}$ & 0,26 & 0,10 & $-0,42$ & 0,03 & 0,46 & - & - & - & - & \\
\hline MPR * & 0,26 & 0,13 & $-0,21$ & $-0,02$ & 0,08 & 0,00 & - & - & - & \\
\hline TDE * & 0,17 & 0,30 & $-0,11$ & $-0,39$ & 0,53 & 0,35 & 0,12 & - & - & \\
\hline ETC * & 0,19 & 0,08 & $-0,33$ & $-0,20$ & 0,49 & 0,60 & $-0,16$ & 0,49 & - & \\
\hline SEL & 0,24 & 0,13 & - & $-0,33$ & 0,43 & 0,21 & $-0,31$ & 0,35 & 0,29 & \\
\hline
\end{tabular}

$p<0,05$

Fuente: Tabla 1

Nota: No es posible realizar la correlación entre las variables SEL y DPP al no haber suficientes casos validos. En SEL (notas de selectividad de los/as estudiantes) no se incluyen daros para universidades privadas, y en DPP (variable que indica la dependencia pública o privada de las universidades) esas mismas universidades tienen asignado el valor 0 .

den a la convergencia. Eso es también adecuado para un índice de calidad global que no transforme a una universidad-de-mujeres en una universidad con más calidad que otra, aunque tenga una estructura mejor en docencia o investigación. MPR mide, hasta cierto punto, un nivel de compromiso social que es esencial en las universidades de excelencia.

Si hubiera que ordenar los seis indicadores básicos según su impacto en la excelencia, nuestra propuesta es situar como más importante la producción de doctores o investigadores (TDE) y, por otro lado, la productividad de las carreras de licenciatura y diplomatura (ETC). Estos dos indicadores son el output del sistema universitario. Modernamente se tiende a dar más importancia al output que al input. Luego se situarían los recursos del sistema, fundamentalmente bibliotecas (LBE) y profesorado (PRO). Como menos importancia, pero también básico, está el número de carreras superiores en la universidad (FET). Por último, el factor más debatible, que nosotros consideramos que influencia la calidad de las universidades, es la proporción de mujeres-profesoras (MPR). Estos indicadores son evaluados a ojo por los estudiantes y sus familias. No hay datos publicados comparables, pero en la duda los/as candidatos eligen la universidad más antigua. Suelen ser más grandes, más universales, con más carreras, se han dedicado bastante más a doctorado, aunque están un poco masificadas (es decir, que la relación estudiantes por profesor es menor). Las universidades más antiguas tienen más recursos y un prestigio mayor. En la duda las familias prefieren enviar a sus hijos/as a las universidades de las regiones más ricas, que son las que atraen más profesorado y se feminizan más. Las zonas ricas ofrecen más oportunidades de todo tipo a las universidades de su área, y a los/as estudiantes.

La nota de selectividad nos indica las preferencias de miles de nuevos estudiantes. La cohorte actual de estudiantes nuevos que ingresan está alrededor de 340.000. La nota de selectividad correlaciona más alto con profesorado (PRO 0,43), y con la producción de títulos de doctor $(0,35)$. En menor medida con el número de centros superiores (FET 0,33). Los candidatos no conocen bien los datos de productividad de las carreras (SEL con ETC correlaciona 0,29 únicamente), y tienen incluso menos información de si la biblioteca de la universidad es buena (LBE 0,21 ). Aunque el $54 \%$ de los nuevos estudiantes son mujeres, no parecen ser muy sensibles al indicador de feminización del profesorado en la universidad, pues la nota media de selectividad y la proporción de mujeres-profesoras correlaciona rela- 


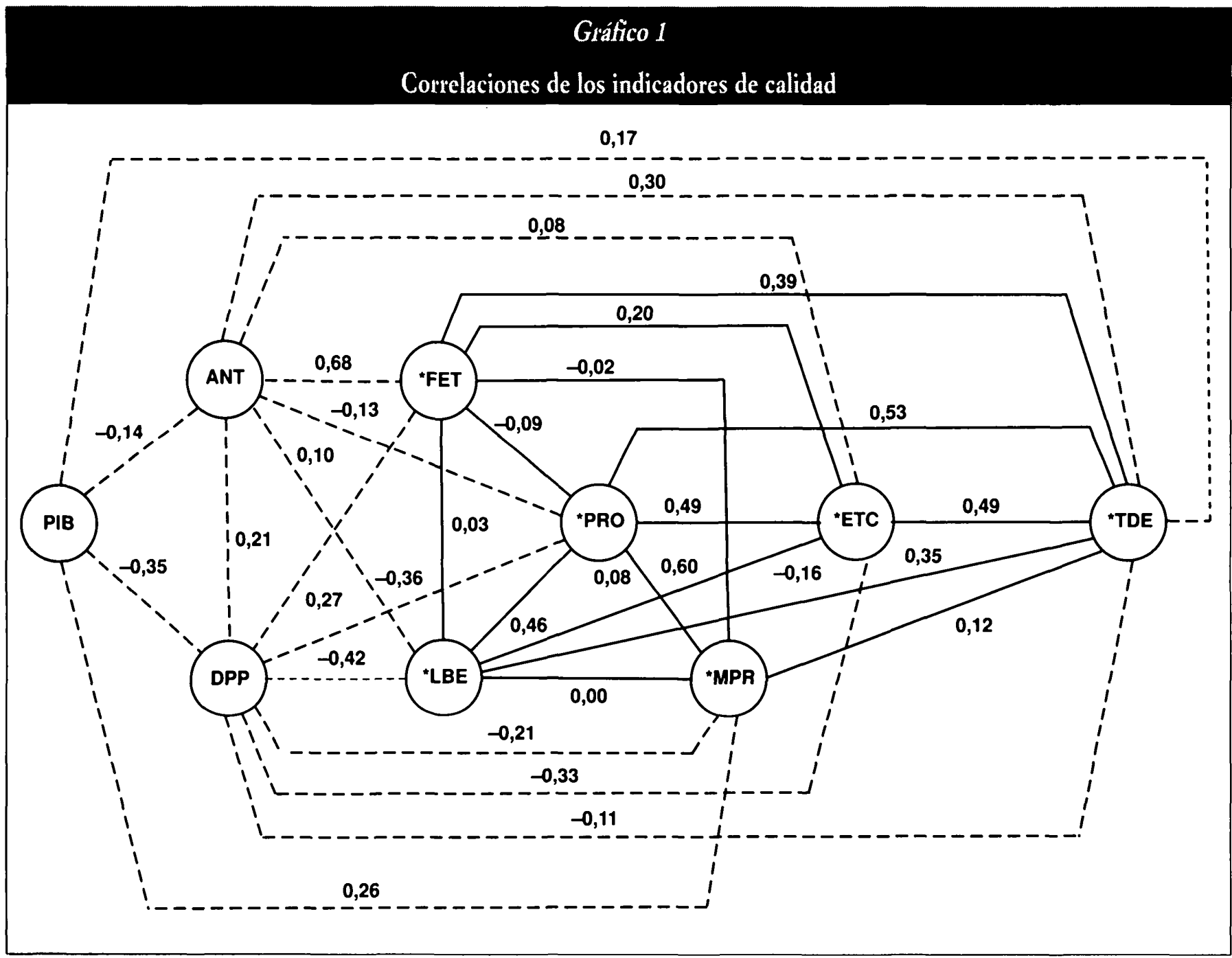

Fuente: Tabla 2.

tivamente alto ipero negativo! $(-0,31)$. Los candidatos se motivan, pues, por las dotaciones de personal docente más que por ninguna otra variable. En el fondo es un tema de oferta-y-demanda, aunque sin información clara por ninguna de las dos partes (ni las familias ni las universidades). Según estos datos que resumen decisiones de 340.000 familias, los/as estudiantes que ingresan se sienten atraídos por las universidades donde a su vez van los profesores (y no las profesoras), donde son más y mejores. También se sienten atraídos por las universidades investigadoras. La nota media de selectividad depende más de la riqueza de la región (correlación 0,24 ) que no por la mera antigüedad de la universidad $(0,13)$.

En el Gráfico 1 se pueden ver las correlaciones fundamentales entre estos indicadores. El número de centros superiores (FET) está muy condicionado por la antigüedad de la universidad $(0,68)$, lo que es esperable. Las universidades más antiguas han tenido más tiempo para crear centros distintos, pero a la vez estuvieron fundadas con un ideal más de universitas, más variado del conocimiento humano y sus distintas especialidades. Algunas universidades nacieron ya con un afán especializador. Pero se sabe que las universidades clásicas no están todas en las zonas más ricas, con lo que el número de centros (FET) no depende de la riqueza $(-0,22$ con PIB). Las universidades más antiguas correlacionan negativamente con riqueza provincial, aunque la correlación no es muy alta (ANT y $\mathrm{PIB}$ es -0,14). Son las universidades públicas las que tienen más centros, porque también son más antiguas (ANT y DPP es 0,21 ) y porque consideran su responsabilidad desarrollar todas las carreras aunque no sean «rentables» económicamente. Así, FET y DPP correlacionan positivamente 0,27 . La imagen es que las universidades más clásicas según este indicador (FET) son de más calidad, y más las públicas que las privadas.

La tasa de profesorado (PRO) correlaciona bastante con riqueza $(0,38$ con $\mathrm{PIB})$. El profesorado, como muchos otros profesionales, son atraídos por las regiones más ricas. La correlación es negativa y significativa con DPP $(-0,36)$ indicando 
que son las universidades privadas las que tienen más profesorado en relación con su tamaño. Suele ser un profesorado más femenino. Es curioso que la tasa de profesorado (en relación con el tamaño de la universidad) no depende nada de la antigüedad de la universidad $(-0,13)$ ni de que tenga más centros $(-0,09)$. El profesorado depende más de la riqueza provincial y de la dependencia privada de la universidad, pues ambas variables están relacionadas (PIB con DPP es $-0,35$ ). El capital humano depende del desarrollo y del mercado privado, lo que no resulta una sorpresa.

El otro recurso de las universidades que se tiene en cuenta en la calidad de la universidad es el número de libros de biblioteca (por cada estudiante), indicador LBE. Los dos recursos - humano y material - correlacionan positivamente, lo que sugiere que los indicadores son apropiados (PRO con LBE es $0,46)$. Este recurso depende mucho también de que la universidad sea privada, pues la correlación DPP con LBE es $-0,42$. Las universidades en zonas ricas tienen más libros $(0,26)$, así como las universidades antiguas $(0,10)$, y las que tienen más carreras $(0,03)$. Son correlaciones positivas, pero muy bajas. Realmente lo que define que la universidad tenga libros es que tenga profesores, y viceversa, o hasta cierto punto que sea una universidad privada.

ETC es un índice general de productividad al medir la proporción de estudiantes de la universidad que terminan la carrera en los años justos, sin repetir año, consiguiendo acabar la carrera en el tiempo previsto. Curiosamente la variable más relacionada con productividad (ETC) es libros (LBE) con la que correlaciona 0,60. Ésta es una correlación alta, para dos indicadores que en principio no tienen por qué estar relacionados. La productividad depende también mucho de la tasa de profesorado $(0,49)$. Con la universalidad de la institución, es decir, el número de carreras (FET), la correlación es positiva pero no tan alta $(0,20)$. La segunda variable que más positivamente se relaciona con la productividad es la dependencia. El que la universidad sea privada expliça mucho la productividad (DPP con ETC es $-0,33$ ). Las universidades privadas garantizan que sus estudiantes terminan la carrera en una elevadísima proporción, y además en los años previstos. La universidad privada es un sistema caro... pero efectivo. Hay una cierta relación positiva de productividad que depende de la antigüedad de las universidades $(0,08)$, o de la riqueza de la región $(0,19)$, pero no son correlaciones muy altas.

La producción de doctores/as (TDE) en una universidad es un indicador excelente de calidad, sobre todo lo que se viene denominando «universidad investigadora». La relación es positiva con los otros cinco indicadores de calidad y bastante alta. Correlaciona 0,49 con productividad (ETC) y 0,53 con la tasa de profesores (PRO). En realidad, TDE es un indicador de productividad de doctorado de las universidades, así que es congruente que correlacione positivamente con ETC que se refiere a la productividad de las carreras de primer y segundo ciclo. Los doctorados dependen de que haya una diversificación de carreras (y Departamentos), con lo que la correlación con FET es 0,39 . La correlación es también alta con bibliotecas (LBE) de 0,35 . Las bibliotecas dependen de que haya profesores y doctores, lo que es congruente. La producción de doctorados correlaciona incluso positivamente con mujeres profesoras (MPR es 0,12 ). TDE es un indicador de calidad, innegable, pero que supone la acumulación de otros indicadores previos de calidad. Depende también de que la universidad sea antigua $(0,30)$. Que esté en una región rica $(0,17)$ es también favorable. Se observa una relación tímida entre las universidades privadas y la producción de títulos de doctor (DPP y TDE correlacionan $-0,11$ ).

Hasta aquí todas las relaciones entre los indicadores de calidad de una universidad son positivos, y en ocasiones bastante altos. Profesorado, productividad y bibliotecas mantienen una relación triangular estrecha. También es importante la relación entre profesorado y doctorado, profesorado y productividad, y productividad y doctorado. Bibliotecas y profesorado van también bastante unidos. El que la universidad sea universal, con bas. tantes carreras (FET), sólo parece tener una incidencia especial en la producción de doctores (TDE). Como puede verse en el gráfico, estos cinco indicadores de calidad forman un conjunto de relaciones estrechas. Miden distintos aspectos de la calidad de la universidad, todos ellos bastante relacionados.

El sexto indicador, proporción de mujeres entre el profesorado (MPR), es un poco especial. No tiene relación con la dotación de profesorado, es decir, que las universidades con mucho profesorado no tienen necesariamente más mujeres profesoras $(0,08)$, no depende nada del número de centros (con FET es $-0,02$ ), y es nula la relación con bibliotecas (con LBE es 0,00$)$. Con referencia a la productividad de las carreras (ETC), el indicador es negativo $(-0,16)$, lo que sugiere que las universidades más productivas son las que menos mujeres tienen entre el profesorado. La única correlación positiva que tiene cierta significación (aunque poca) es con la productividad de doctores (MPR con TDE es 0,12). El indicador MPR es, pues, de otro nivel, o tiene otra significación. Las universidades con una proporción mayor de mujeres profesoras no son las que tienen indicadores altos de calidad, pero tampoco bajos. No tiene relación con los otros cinco indicadores de calidad, e incluso a veces esa relación es negativa. El que haya mujeres profesoras depende más bien de que la región sea desarrollada $(0,26$ con PIB $)$, algo con que la universidad sea antigua $(0,13)$, y sobre todo es una característica de universidad privada $(-0,21$ con DPP). El efecto de la feminización del profesorado en la productividad general de las carreras es negativa, y sólo se nota su efecto en títulos de doctorado, que pueden ser precisamente los propios de ese mismo colectivo de mujeres pro. fesoras, pues la relación entre títulos de doctor y profesorado 
total es alta $(0,53)$. En cualquier caso, MPR es un indicador del compromiso y diversidad de una universidad, y debe ser tenido en cuenta para medir ese tercer aspecto de una universitas, además de docencia e investigación.

Con estos datos se demuestra que la elección de los indicadores de calidad (entre los 71 indicadores del estudio original) es apropiada, pues miden consistentemente diversos aspectos de la calidad de las universidades, guardando siempre relaciones positivas entre ellos, y a menudo una correlación alta. Forman una macla o cluster de indicadores altamente relacionados. MPR es la excepción que no correlaciona positiva ni negativamente con los indicadores de calidad, sino más bien con que la universidad tenga más solera, sea privada, y esté en una región desarrollada. Hay una cierta idea de modernidad en tener más mujeres profesoras que se comprueba mediante estos datos y otros anteriores. MPR no es un indicador de calidad de las universidades al mismo nivel, sino más bien de compromiso social, de no-discriminación, y de diversidad; por eso debe ser incluido en la fórmula final. Precisamente, el que las correlaciones no sean altas es un indicador de que existe esa discriminación en contra de las mujeres. La proporción global de mujeres profesoras es $33 \%$, pero oscilando entre $18 \%$ y $45 \%$ en universidades extremas. Mientras ese indicador no aumente hasta $50 \%$, que sea bajo, y las correcciones no altas con otros indicadores es parte de un proceso de discriminación más profundo. Lo más difícil es superar el $40 \%$ hasta el $50 \%$, pues las mujeres no se doctoran más que en un $40 \%$ del total. Se van, pues, a necesitar varias décadas más. Las universidades «de prestigio» siguen siendo de varones, y donde los varones tienen el poder. El dato de que las mujeres sean $58 \%$ de los estudiantes que terminen la carrera, $40 \%$ de los títulos de doctor, $33 \%$ de las mujeres profesoras, y solamente $14 \%$ del cuerpo de catedráticos indica ya un nivel de discriminación y de falta de diversidad grave en la universidad española.

Los coeficientes de correlación miden relaciones lineales entre dos indicadores. Es posible que entre algunas de estas variables fundamentales no haya una correlación alta, pero sí una relación interesante. La visualización de algunas de estas relaciones permite entender la existencia de relaciones diferentes, o la existencia de casos anómalos. En el Gráfico 2 se puede ver la relación entre la tasa de profesorado y el número de libros en las bibliotecas universitarias por estudiante. La correlación lineal es 0,46 , lo que supone una relación relativamente estrecha. Ambos indicadores - profesores, y libros en la biblioteca- están en relación al tamaño relativo de cada universidad medido en número de estudiantes. Las universidades son bastante homogéneas. Forman casi todas un núcleo en torno a 6 profesores (por cada cien estudiantes) y 12 libros por estudiante. La relación es bastante estrecha, mostrando que las universidades que están bien de equipamiento también lo están de profesorado, y al revés. Las universidades privadas son más

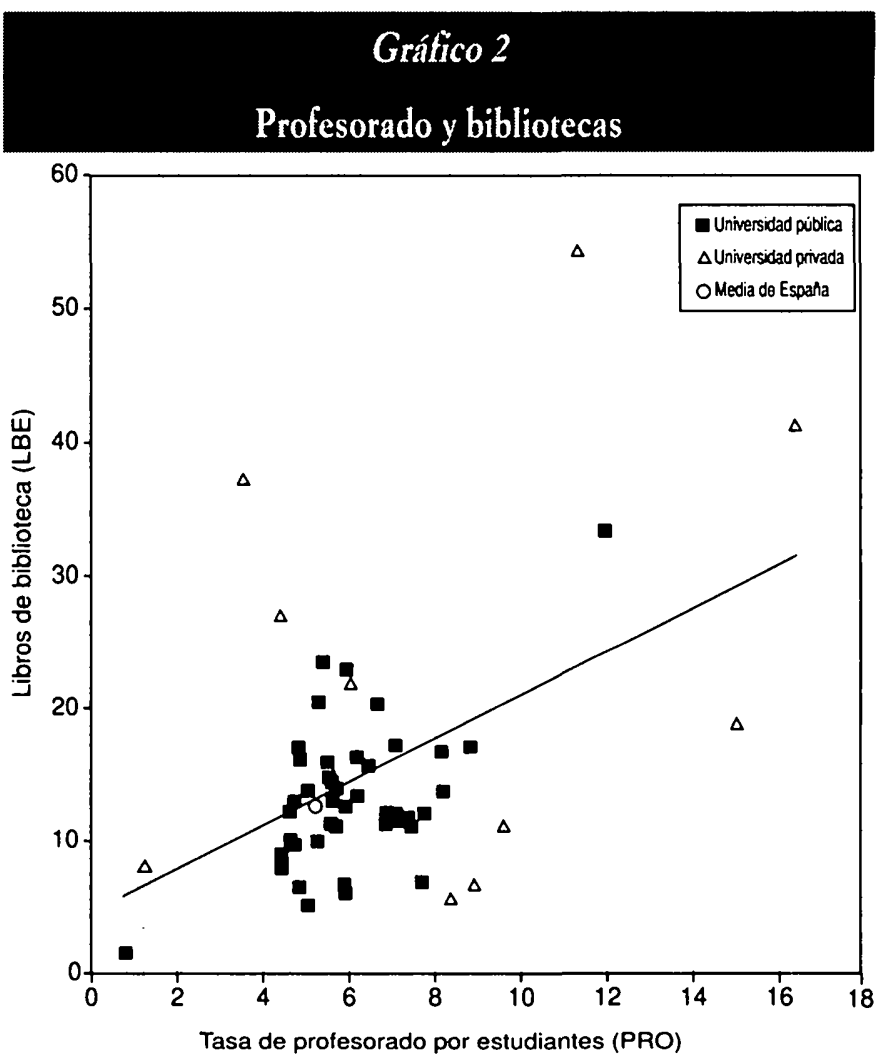

Nota: PRO es la tasa de profesorado por cien estudiantes y LBE es el número de libros de la biblioteca por estudiante. Ambos correlacionan 0,46. La linea muestra la regresión lineal. Se calculan los cuadrados menores respecto a una línea representada por la ecuación: $Y=m X+b$, donde $m$ es la pendiente y b el intercepto.

dispersas, siguiendo pautas un poco diferentes. Hay privadas con bastantes profesores, pero pocos libros, que son las universidades nuevas, de forma más exagerada la Universidad Antonio de Nebrija, que destaca con muchos profesores y pocos libros. En cambio, lo normal de las privadas clásicas es lo contrario, es tener muchos más libros que profesores. Es el caso de la Pontificia de Salamanca, y sobre todo de Deusto. Esta última destaca por una buena biblioteca pero pocos profesores, seguramente trabajando a tiempo completo. En lo alto de todo, con una dotación excelente de ambos recursos, están Pontificia de Comillas, y Navarra. Navarra es la universidad más avanzada de todas, con muchos libros y muchos profesores. Hay una universidad pública que destaca muy por delante de las demás, con una clara inversión en libros y profesores, que es Pompeu Fabra. Así se explica su posición tercera en el ranking de universidades públicas. También la posición muy destacada de Navarra y Pontificia de Comillas en el ranking general (siendo las dos primeras) queda evidente por su inversión cuantiosa en recursos humanos y materiales. Atrás del todo en el gráfico aparecen las dos universidades a distancia (UOC y UNED) que para sus tamaños relativos lógicamente no necesitan ni tantos profesores ni tantos libros. Las medidas usuales de calidad no son aplicables directamente a la estructura de universidades a distancia. Su posición retrasada es exacta (pues está medida 
con indicadores claros), pero no representa las necesidades reales de esas dos universidades.

El resto de las universidades públicas se centra en unos parámetros parecidos, lo que indica que hay un control férreo de los recursos, haciéndolos iguales entre todas las universidades. Incluso las universidades politécnicas, que tienen pocos libros y muchos profesores, no destacan fuera del núcleo central, aunque están en la parte de abajo. No son, pues, muy disimilares al conjunto de universidades públicas a pesar de su especialización en Escuelas Técnicas Superiores. De universidades públicas sólo Pompeu Fabra ha logrado escapar al núcleo. No queda claro durante cuánto tiempo lo conseguirá. Si aumenta de tamaño (número de estudiantes) es posible que sus tasas elevadas de libros y de profesorado desciendan. Las universidades privadas que controlan el número de estudiantes aparecen con más recursos que las públicas; las más antiguas destacando en libros y las nuevas en profesorado. La correlación lineal de 0,46 aparece, pues, más clara de lo previsto gracias a la concentración en un modelo convergente que es el dominante en el sector público.

No conviene ser intuitivo en las relaciones entre recursos y resultados. Las correlaciones muestran que la relación entre profesorado y productividad es positiva y alta $(0,49)$, pero es aún más alta entre biblioteca y productividad $(0,60)$. La relación más débil del triángulo es la que existe entre profesores y biblioteca, que es la que acabamos de ver. Sin embargo, se observa que es una relación lineal clara con un núcleo consistente que supone para las universidades públicas unos estándares similares de recursos, a los que sólo se escapa hacia adelante Pompeu Fabra y hacia atrás UNED. El Gráfico 3 presenta la relación entre el profesorado y la productividad de las carreras, medida por la proporción de estudiantes que terminan la carrera en los años justos. Es una correlación muy similar a la anterior, un poco mayor; de 0,49 . El núcleo inicial se alarga: la tasa de profesorado sigue bastante concentrada en torno a $6 \%$ estudiantes, pero la productividad - medida en proporción de estudiantes que terminan la carrera en los años justos- varía bastante más. Las universidades menos productivas se sitúan en torno a $30 \%$ y las más productivas alcanzan $80 \%$. Hay, además, una avanzada de universidades públicas y sobre todo privadas que destacan por tener mucho profesorado y además ser muy productivas. La punta de lanza es Navarra, que según todos los indicadores es una universidad excelente. Le sigue Pompeu Fabra (la universidad pública que más destaca), detrás Pontificia de Comillas, y Autónoma de Barcelona. Junto con Pompeu Fabra la Universidad Autónoma de Barcelona destaca claramente mostrando tasas altas de profesorado, pero sobre todo de productividad.

En la parte de abajo hay una serie de universidades (sobre todo públicas) que tienden a tener poco profesorado y una

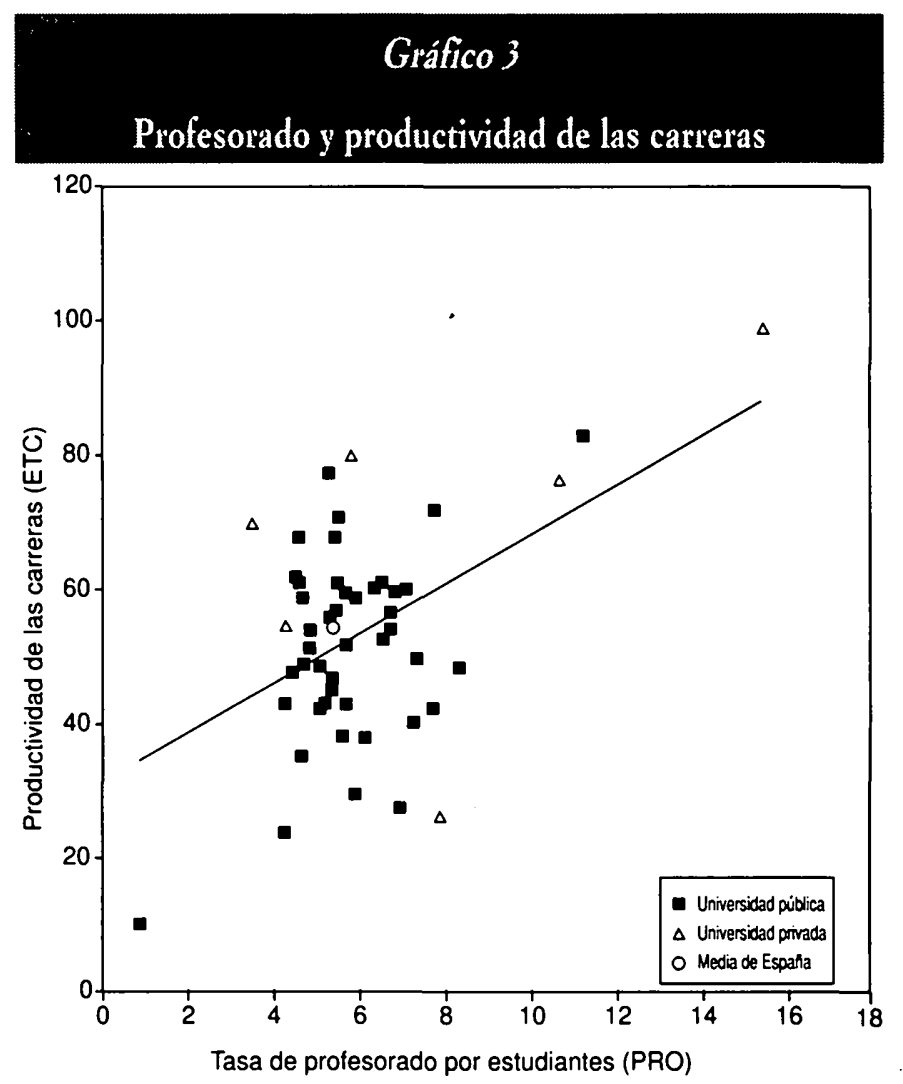

Fuente: Tabla 1.

Nota: PRO es la tasa de profesorado por cien estudiantes y ETC es la proporción de estudiantes que terminaron la carrera en los años justos (en porcentajes). Ambos correlacionan 0,49. La línea muestra la regresión lineal. Se calculan los cuadrados menores respecto a una linea representada por la ecuación: $\mathrm{Y}=\mathrm{mX}+\mathrm{b}$, donde $\mathrm{m}$ es la pendiente $\mathrm{y} b$ el intercepto.

productividad bajísima. La más atrasada es UNED, donde terminan la carrera en los años justos menos del $15 \%$ de sus matriculados (la mayoría son varones). Luego están Huelva, Las Palmas, Rovira i Virgili, y la única privada: San Pablo CEU. Las universidades privadas tienen una productividad mucho mayor que las públicas. En lo alto del gráfico se pueden ver dos privadas: Deusto con poco profesorado, y Ramón Llull con algo más de profesorado; pero ambas con muy buena productividad. El caso de Deusto es peculiar, pues tiene pocos profesores, pero está bien de otros recursos y productividad. Quizás hay una ocultación de profesorado, o el profesorado trabaja demasiadas horas. No se explica. Este gráfico muestra bastante bien la calidad diferencial de las universidades españolas. La inversión en personal docente explica la productividad de la universidad, que a la postre es el indicador fundamental de calidad. Lógicamente, habría que medir además lo que aprenden los estudiantes de Navarra, Pompeu Fabra, Comillas, o Autónoma de Barcelona -en relación con Huelva, Las Palmas, o Rovira i Virgili-, pero no hay duda de que además de terminar la carrera en mayores porcentajes el estudiantado termina mejor preparado. Estos gráficos permiten entender las relaciones entre universidades. 
El tercer gráfico de este triángulo entre profesores, biblioteca, y productividad es el más definitorio para entender todas las relaciones. El Gráfico 4 presenta la relación entre libros de biblioteca (medido por estudiante) y productividad (porcentaje de estudiantes que terminan la carrera en los años justos). Es la correlación más alta — de 0,60 - que pone en evidencia la interconexión importante entre indicadores: los recursos invertidos (libros) y la productividad. Las universidades presentan una pauta más diferenciada, aunque todavía es visible un núcleo compuesto exclusivamente por universidades públicas. En la periferia de ese núcleo están las universidades privadas. Al frente de la tendencia lineal se sitúan universidades en forma de parejas. Delante del todo están Navarra (con muchos libros, pero sobre todo con una productividad máxima), y Pontificia de Comillas, la máxima de libros pero no de productividad. La segunda pareja está formada por Pompeu Fabra con una excelente productividad, y Deusto con más libros que productividad, pero también muy destacada. Detrás hay dos privadas: Ramón Llull y Pontificia de Salamanca. En la parte superior del núcleo destaca Complutense, que es una excelente universidad con buena productividad.

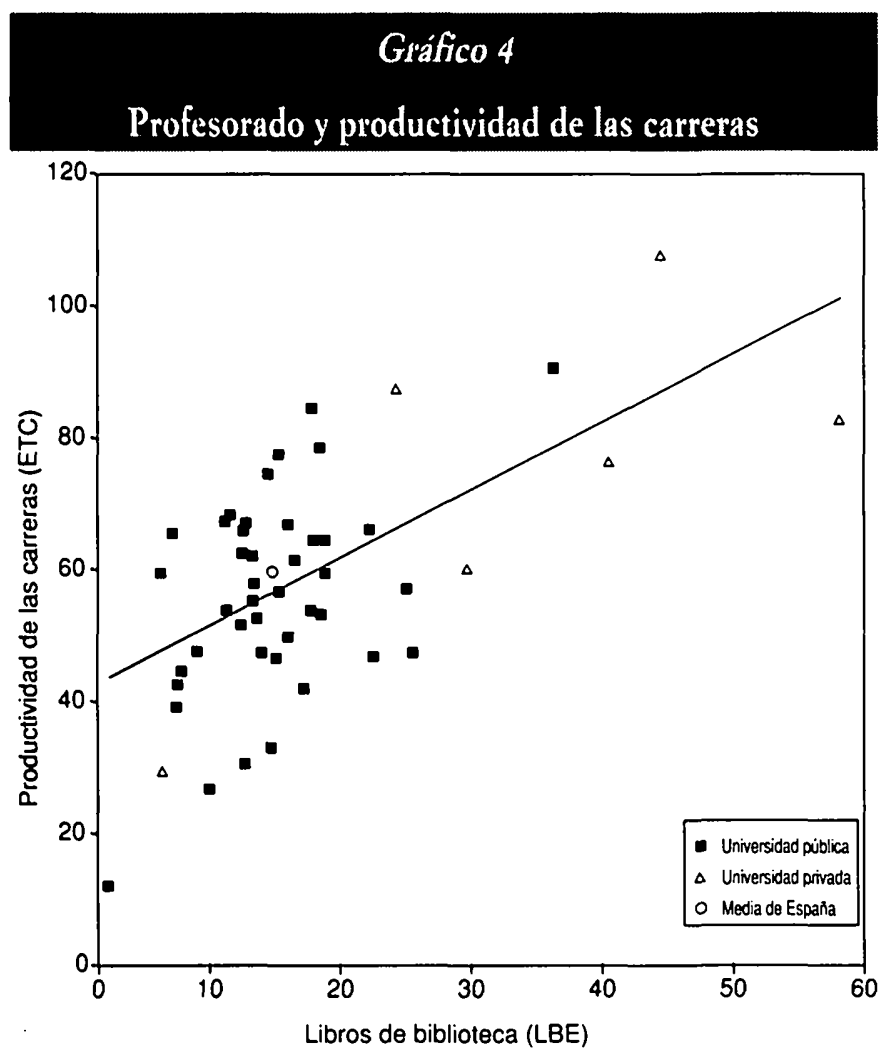

Fucnte: Tabla 1.

Notn: LBE es el número de libros de biblioteca por estudiante y ETC es la proporción de estudiantes que terminaron la carrera en los años justos (en porcentajes). Ambos correlacionan 0,60. La linea muestra In tendencia utilizando una regresión lineal. Se calculan los cuadrados menores respecto a una linea repre. sentada por la ccuación: $Y=m X+b$, donde $m$ es la pendiente y $b$ el intercepto.
En la parte inferior del gráfico, y atrás del todo, está UNED, que destaca siempre por indicadores muy bajos. Al ser «a distancia» no necesita muchos libros; pero no se justifica tan fácilmente su productividad bajísima. La privada más cercana es otra universidad a distancia, ésta privada: Universitat Oberta de Catalunya (UOC). UNED y UOC son ambas de productividad baja, universidades fundamentalmente para estudiantes varones que seguramente trabajan al tiempo que estudian. Las otras universidades públicas que destacan por su baja productividad son Huelva, Rovira i Virgili, y Las Palmas. La distribución en este gráfico es más lineal, acentuando así el coeficiente de correlación $(0,60)$, y mostrando una relación estrecha entre recursos de equipamientos (en este caso libros) y productividad de las universidades. Representa, pues, una asociación esperable entre inputs y outputs, entre recursos y resultados.

Cuando se agrupan las universidades en núcleos se notan mejor las tendencias. Esto aparece en el Gráfico 5, que es idéntico al anterior, pero con el dibujo de las superficies que contienen a las distintas universidades. Es una distribución muy explicatoria de la relación entre recursos y resultados, y en ese sentido visualiza la excelencia de las universidades. No hay secreto: una buena universidad invierte en muchos recursos. No podría ser de otra manera. El que esté en una región desarrollada, o que sea antigua, ayuda pero no es definitorio.

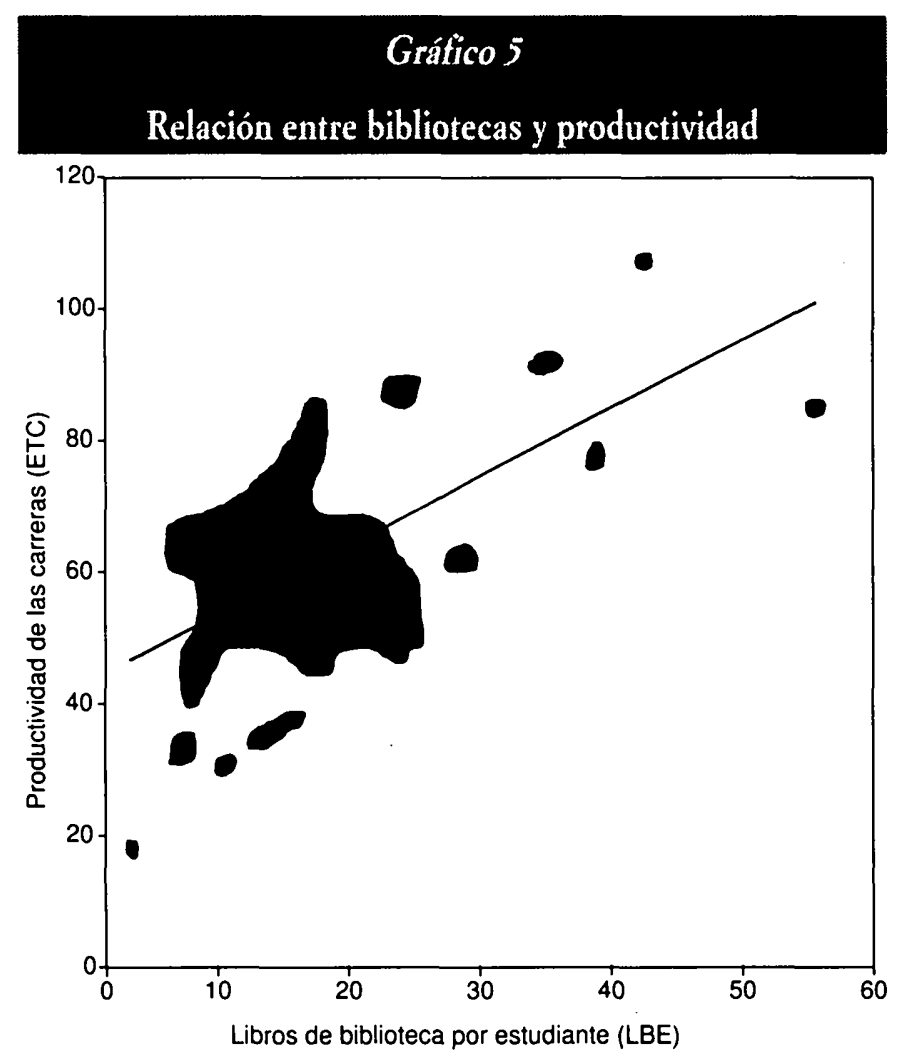

Fuente: Gráfico 4. 
Lo importante es invertir recursos, humanos y sobre todo materiales. No hay, pues, ningún misterio ni fórmula especial. El núcleo central permite algunas tendencias interesantes, pero funciona de acuerdo a una pauta esperada. Sólo algunas universidades se destacan, invirtiendo más y obteniendo una mayor productividad. Otras invierten menos y obtienen una productividad baja. En algunos casos la productividad es proporcionalmente mayor y en otros menor a los recursos invertidos. Pero la tendencia general es bastante precisa. Este gráfico es el más llamativo del estudio, pues permite entender la relación dialéctica entre recursos y producción.

El núcleo central está compuesto únicamente por universidades públicas. En España la Administración Pública ha mantenido durante años un control férreo de su sistema universitario, para que todas las universidades se pareciesen. Es lo que castizamente se denomina «café para todos». Ha logrado un sistema convergente, isomórfico, pero de calidad baja, y poco competitivo a nivel internacional. Sólo algunas universidades privadas se han escapado a este modelo, pero lo han hecho más por negocio que por destacar internacionalmente. La universidad pública barcelonesa Pompeu Fabra trata de escaparse - hacia adelante- de esta tendencia centrípeta, pero no queda claro si lo logrará en el futuro. Es todavía una universidad muy joven. Pero no se trata de que cambie una universidad, sino de que se transforme todo el sistema universitario español. Ésa es la asignatura pendiente en el siglo XXI.

Un excursus comparativo puede explicar mejor la situación deficiente de recursos, sobre todo de bibliotecas, de las universidades españolas. La media de libros de todas las universidades españolas (públicas y privadas) es 404.000 volúmenes por biblioteca. Solamente hay dos universidades que superen el millón de volúmenes: Complutense con 2,1 millones y Barcelona con 1,5 millones. La tercera es Sevilla con casi un millón, y luego Valencia con 928.000 volúmenes. Salamanca -la segunda universidad más antigua del mundo- tiene sólo 833.000 ejemplares en la biblioteca. Las universidades con bibliotecas más pequeñas son Universitat Oberta de Catalunya con 12.000 volúmenes, Alfonso X el Sabio con 20.000, y Antonio de Nebrija que tiene 22.000 volúmenes. Pero incluso universidades públicas, como Almería, tienen solamente 92.000 ejemplares, o Burgos 59.000. Son cantidades exiguas. Se entiende que para que una universidad pueda mínimamente ser considerada como universidad-investigadora necesita al menos dos millones de volúmenes en la biblioteca. Esta cantidad es sólo alcanzada por la Universidad Complutense de Madrid.

La Association of Research Libraries publica anualmente su ranking de bibliotecas universitarias combinando Estados Unidos y Canadá (2000: A23). Las cien primeras universidades tienen todas más de dos millones de volúmenes, independientemente del número de estudiantes. Por ejemplo, una universidad como Georgetown University, con unos 12.000 estudian- tes, tiene 2,4 millones de volúmenes, y eso se considera escaso. Las diez primeras universidades de Estados Unidos y Canadá tienen cada una más de 7 millones de volúmenes en la biblioteca. Las diez siguientes (es decir, de la 11. ${ }^{a}$ a la 20. ${ }^{a}$ ) tienen entre 5 y 7 millones cada una. Las tres primeras universidades en biblioteca son Harvard University con 14,2 millones de volúmenes, Yale University con 10,3 y University of Illinois at Urbana-Champaign con 9,3. Hay que tener en cuenta que todas las universidades de España apenas si reúnen 21,8 millones de volúmenes.

No hay secreto para conseguir una buena biblioteca, pues las universidades españolas son mucho más grandes, y mucho más antiguas (de media ciento veinticuatro años, pero hay seis universidades medievales). Tampoco es problema de haber tenido tiempo en construir una buena biblioteca. Harvard University, por ejemplo, sólo en un año (el de referencia, 1998-1999) añadió 308.843 volúmenes a su biblioteca, es decir, bastante más que todos los libros que tiene la Universidad Politécnica de Cataluña (265.000, es decir, un 16\% más). Harvard University tiene 1.040 personas trabajando en la biblioteca. Se calcula que aproximadamente se necesita una persona traba. jando por cada diez mil libros. El presupuesto realmente gas. tado en ese año en biblioteca por Harvard supera los 15.000 millones de pesetas ${ }^{3}$. Mantiene activas 105.837 colecciones de revistas. Con esas cantidades la situación española no puede ser más deficitaria. Universidades con vocación de universidad-investigadora, de excelencia, como Pompeu Fabra, apenas tiene una biblioteca con un cuarto de millón de volúmenes. Incluso Navarra (privada) que es la mejor universidad española según la mayoría de criterios, tiene una biblioteca de solamente 596.000 ejemplares.

La Association of Research Libraries no sólo ordena las universidades por número de volúmenes en la biblioteca, con Harvard y Yale a la cabeza superando los diez millones cada una (14,2 y 10,3 respectivamente), sino que además calcula un ranking utilizando cinco indicadores. Esos indicadores son: número de volúmenes totales, número de volúmenes añadidos en el último año, número de colecciones de revistas, coste anual de funcionamiento, y número de personal permanente en la biblioteca. Con esos cinco indicadores combinados calcula un ranking ordenando las universidades de la primera a la 111. ${ }^{a}$ Aproximadamente las universidades aparecen en el ranking por número de volúmenes, pues suele coincidir que además las bibliotecas mayores son las que más invierten. Pero algunas dedican en el último lustro un esfuerzo especial para dotar sus bibliotecas. Es el caso de la University of Notre Dame que incrementó su gasto en libros en $68 \%$ en los últimos cinco años, o, por ejemplo, Stanford University $48 \%{ }^{4}$. Las universidades investigadoras en Estados Unidos y Canadá añaden anualmente a sus bibliotecas al menos cien mil volúmenes nuevos, gastando más de 4.000 millones de pesetas anuales cada universidad. 
No hay secreto especial para construir una buena biblioteca, salvo dedicar recursos adecuados de personal y monetarios, muy por encima de lo que están haciendo las universidades españolas. Cada año que pasa el desnivel entre las universidades españolas (todas) y las mejores universidades investigadoras del mundo es mayor.

Otra forma de medir la productividad de las universidades es la formación de doctores e investigadores. Las tasas son muy bajas en España, aunque hay diferencias importantes. En el Gráfico 6 se observa la relación entre las tasas de profesorado y los títulos de doctor que se conceden en cada universidad. Hay que tener en cuenta que en algunos casos son las mismas personas (profesores y doctores). La correlación entre ambas variables es 0,53 . La distribución es en abanico: cuando crece la dotación de profesores la producción de títulos de doctor (por mil estudiantes) varía cada vez más, es decir, hay una cierta pauta divergente. Eso significa que el aumento de profesorado es un factor necesario pero no suficiente para lograr una verdadera universidad investigadora. La tarea posterior es definir esos otros factores que, añadidos a una mayor dotación de profesorado, consiguen producir doctorados. Una variable que ya conocemos es precisamente la antigüedad de la universidad. El gráfico muestra diversos tipos de universidades, según los niveles del «abanico». En la parte más retrasada están como casi siempre las universidades a distancia (UNED y UOC) que no tienen mucho profesorado, pero tampoco producen doctorados. Luego está el núcleo fundamental de universidades, en donde las privadas están en una situación inferior: tienen más profesorado que doctorados. Las universidades privadas, sobre todo las más nuevas, no están interesadas en formar investigadores. Hay una tercera línea - precisamente en forma de línea- que han desarrollado más recursos de profesorado (siempre en tasas por mil estudiantes) y consiguen resultados variables del doctorado. Tres universidades excelentes consiguen bastantes doctorados: Autónoma de Madrid arriba (bastante destacada), Autónoma de Barcelona, y La Laguna. Las autónomas nacieron con un modelo de universidad investigadora. En cambio, por debajo de la línea de regresión, con más profesores que doctores relativamente hablando, están Pontificia de Comillas, Pompeu Fabra, y Antonio de Nebrija. Esta última no produce títulos de doctor. Pompeu Fabra destaca por ser una universidad de excelencia, pero que le faltan programas de doctorado y producción de títulos de doctor. Es un excelente college, pero no tanto (todavía) una universidad investigadora.

Delante de todo, como una estrella en el firmamento del gráfico, en la esquina derecha, está la Universidad de Navarra. Esa universidad destaca por una dotación de profesorado muy considerable, y además por una producción llamativa de títulos de doctor. No parece tener nada en común con el resto de universidades españolas. Es preocupante que el modelo sea

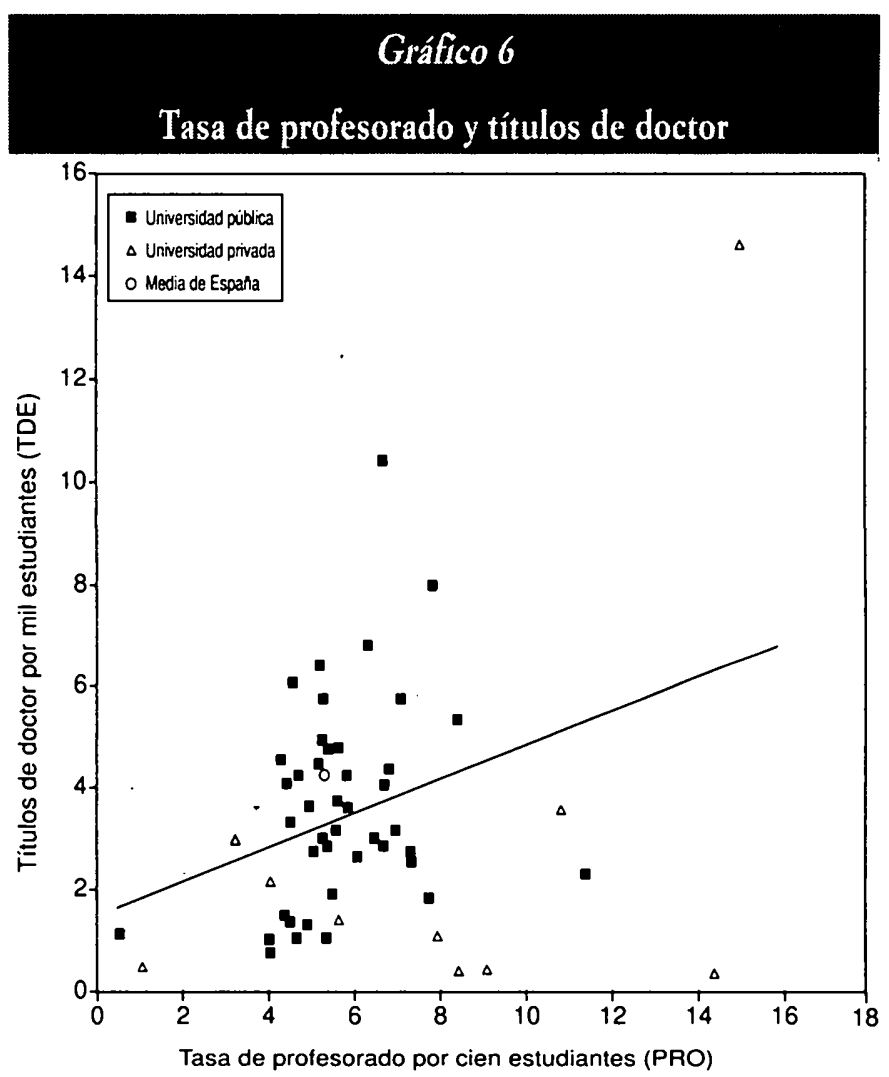

Fuente: Tabla 1.

Nota: PRO es la tasa de profesorado por cien estudiantes y TDE los titulos de doctor por mil estudiantes. Ambos correlacionan 0,53. La linea muestra la regresión lineal. Se calculan los cuadrados menores respecto a una linea representada por la ecuación: $Y=m X+b$, donde $m$ es la pendiente $y$ b el intercepto.

divergente, es decir, que las universidades según aumentan sus tasas de profesorado (que en general son bajas) no necesariamente consiguen desarrollar el tercer ciclo. Unas sí lo consiguen (como las autónomas) pero otras no lo logran. El modelo puede llevar a tipos diferentes de universidades, al estilo de Estados Unidos, con universidades de formación humanística de primer y segundo ciclo, y otras universidades realmente investigadoras. Pero es pronto para establecer esa línea de tendencia. Es posible que el desarrollo del tercer ciclo en España pase todavía por procesos distintos. Con los datos actuales no es posible predecir ese futuro.

Quizás lo que explique más el desarrollo del tercer ciclo no sean los recursos (como tasa de profesorado), sino los resultados globales del primer y segundo ciclo. Las universidades que consiguen diplomar o licenciar más estudiantes, y en un tiempo menor, pueden concentrar recursos humanos en el tercer ciclo, y además tener mejores estudiantes para seguir hacia el doctorado. El Gráfico 7 explora esta posibilidad. Presenta la productividad de las carreras (medida por el porcentaje de estudiantes que se gradúan en el número de años precisos) influenciando la tasa de títulos de doctor (por mil estudiantes, como siempre). La correlación es también relativamente alta 


\section{Gráfico 7}

\section{Productividad de las carreras y títulos de doctor}

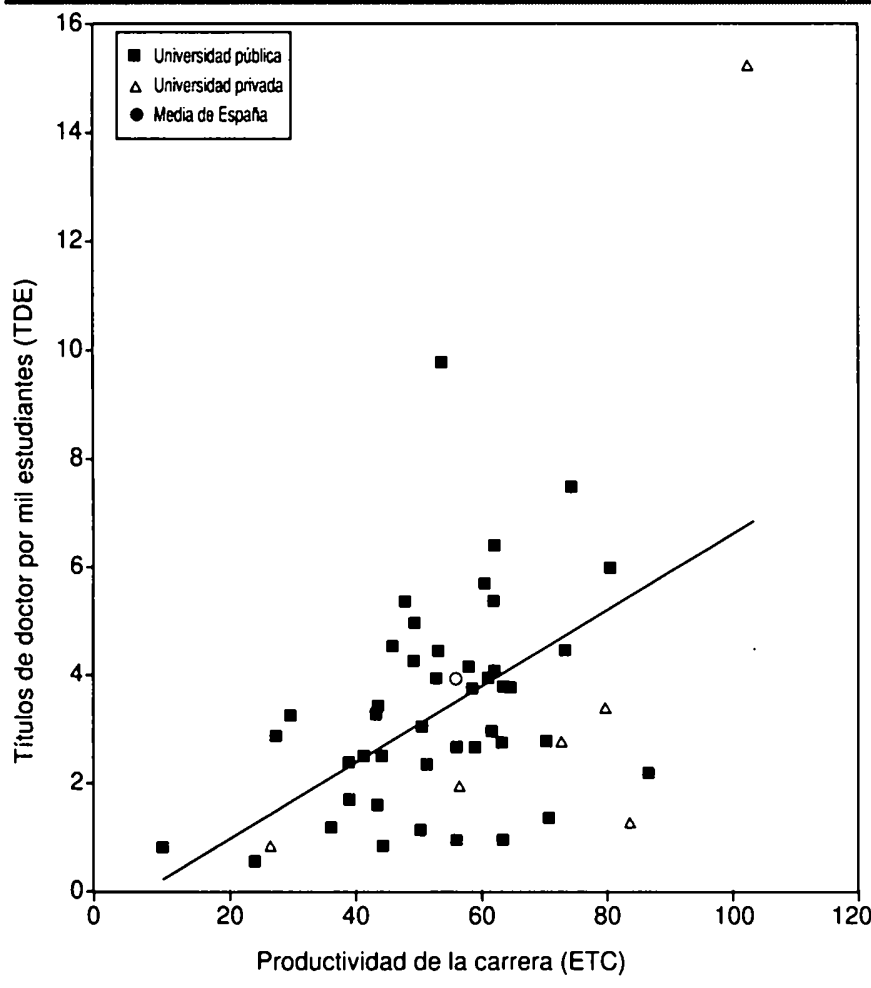

Fuente: Tabla 1

Nota: ETC es la proporción de estudiantes que terminaron la carrera en los años justos (en porcentaje), y TDE los títulos de doctor por mil estudiantes. Ambos correlacionan 0,49. La línea muestra la regresión lineal. Se calculan los cuadrados menores respecto a una linea representada por la ecuación: $Y=m X+b$ donde $m$ es la pendiente y b el intercepto.

$(0,49)$. La distribución es bastante lineal, pero continúa con la pauta de divergencia. Cada vez las universidades se diferencian más, y no lo contrario. Esta pauta, que parece inevitable, a lo mejor es la causa en el futuro de una reforma efectiva del sistema universitario español. Cuando la productividad del primero y segundo ciclo aumenta, así lo hace también la producción de doctores. Unas cuantas universidades no parecen interesadas por el tercer ciclo, mientras que otras destacan por ese interés. Arriba del todo está otra vez Navarra. A distancia, pero también destacada, se observa la Universidad Autónoma de Madrid.

Más que mirar la distribución de las universidades en forma de franjas de izquierda a derecha, o de abajo arriba, es útil diferenciar a las universidades por si se acercan o alejan de la norma. La conducta estándar es la más cercana a la recta de regresión. De tal forma que se podría analizar la distribución de las universidades en tres grupos: a) universidades que a igual. dad de productividad se preocupan mucho por desarrollar programas de doctorado (están todas por encima de la recta, y a una cierta distancia); b) universidades que se ocupan del doctorado tanto como de la productividad del resto de las carreras (se ajustan bastante a la recta, y se sitúan muy próximas a la misma); y c) universidades que se interesan poco o nada por desarrollar programas de doctorado, independientemente de la productividad general que consiguen en sus carreras (están por debajo de la recta de regresión y a una cierta distancia).

El primer grupo denota la excelencia de las universidades. En la lista de ese primer grupo está Navarra, las dos autónomas, Barcelona, Alcalá de Henares, Santiago, Granada, La Laguna, Salamanca, etc. Es decir, universidades excelentes, que no sólo se dedican a producir estudiantes de primer y segundo ciclo, sino que concentran esfuerzos en el doctorado. En el segundo grupo de productividad y doctorado ajustado a la media, se encuentran la mayoría de las universidades públicas; desde Complutense (la más delantera) a UNED (la más atrasada). No hay universidades privadas en este grupo. Incluye dos politécnicas, las universidades con estudios más técnicos, y un número variado de universidades de calidad media. El tercer grupo contiene universidades que deciden no desarrollar el tercer ciclo, y que se concentran en carreras de primer y segundo ciclo. A excepción de Navarra que sí desarrolla doctorado (y mucho) aquí están todas las privadas. También hay algunas públicas: Castilla-La Mancha, Extremadura, La Rioja, Lleida, Politécnica de Valencia, Burgos, Cádiz, La Coruña, Girona, Jaén, y Vigo. Llama la atención que en este grupo estén Pompeu Fabra, Carlos III, y País Vasco. Las tres son universidades con vocación de universidades investigadoras, pero que relativamente hablando no lo están consiguiendo. El gráfico requiere bastantes matizaciones. Hay que recordar que la variable productividad es una de las que más ha costado calcular, y en donde los datos aparecen a veces incompletos o confusos. De todas formas, la correlación es alta, sugiriendo que la relación es diver. gente pero estable.

Compara dos cosas un poco distintas: productividad de primer-y-segundo ciclo con la producción de títulos de tercer ciclo Quizás sea más interesante medir la productividad del primer/segundo ciclo directamente con la productividad del tercer ciclo, aunque al alargar el período de estudio la correlación sea lógicamente más baja $(0,38)$. El Gráfico 8 señala las relaciones entre la productividad de las carreras y de doctorados. Ambos se miden por la proporción de estudiantes que terminan los estudios en los años justos: tres años en las carreras cortas (de primer ciclo), cinco años en las carreras largas (de segundo ciclo), y cuatro años en el doctorado (también llamado tercer ciclo). La correlación es positiva pero relativamente baja $(0,38)$. La variable DTD, productividad de doctorado, no se incluye en las variables básicas para medir la excelencia de las universidades, pues su distribución es un poco extraña. Algunas universidades conocidas como no-buenas consiguen niveles altos en esta variable, y otras reputadas como universidades de calidad obtienen porcentajes que no son bajos, pero que están cercanos e incluso por debajo de la media. Eso es evidente 


\section{Gráfico 8}

Relación cntre la productividad de la carrera y del doctorado

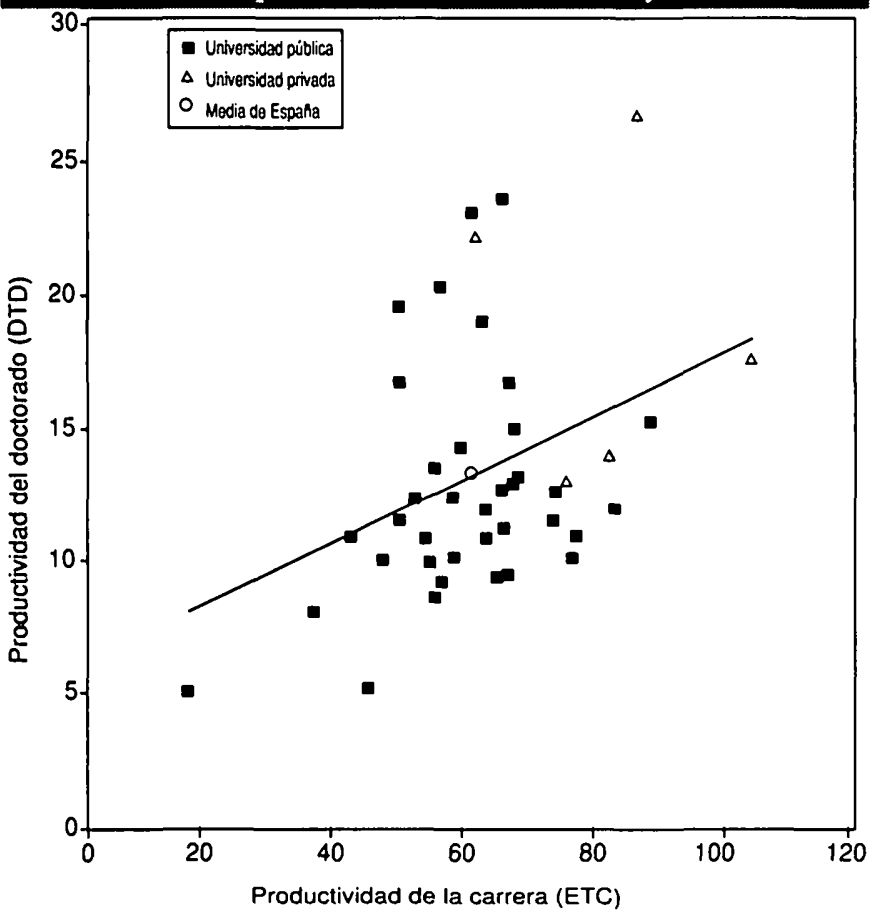

Nota: ETC es la proporción de estudiantes que terminaron la carrera en los años justos (en porcentajes) y DTD cs el porcentaje de doctorandos que terminan la carrera en cuatro años. Ambos correlacionan 0,38. Ln línen mucstra la regresión lineal. Se calculan los cuadrados menores respecto a una linea representada por la ecuación: $Y=m X+b$, donde $m$ es la pendiente y $b$ el intercepto.

en la distribución de universidades en el gráfico, que es dispersa, y sin un núcleo preciso. Incluso se observa una cierta divergencia, señalada ya antes. La divergencia supone que las universidades al desarrollarse deciden por dedicarse a doctorado o abstenerse. La decisión seguramente no es lógica, ni siquiera explícita en los documentos de la universidad, sino que depende de otros factores.

La productividad del doctorado - medida mediante el porcentaje de doctorandos/as que realizan los estudios, terminan la tesis y la aprueban en cuatro años- es muy baja en España. Está por debajo del $13 \%$. No queda claro qué factores logran que ese porcentaje aumente. Entre las universidades que lo logran hay dos privadas: Ramón Llull y Pontificia de Salamanca. Entre las públicas están Santiago, Carlos III, León, Girona, Oviedo, Pública de Navarra, y Barcelona. No hay nada en común entre esas universidades. Las buenas universidades privadas (Navarra, Pontificia de Comillas, y Deusto) están por debajo de la recta de regresión. Tampoco esto se explica fácilmente. Entre las públicas las más retrasadas son Las Palmas, Jaume I de Castellón, y UNED. Esto es ya más explicable por las relaciones anteriores.

Estos gráficos apoyan la idea de que el doctorado es un añadido a las universidades españolas, que tiene poca impor- tancia, y que se considera todavía como un sistema de formación interna del personal docente. No es mucho más. Tendrán que pasar bastantes años para que se pueda analizar el doctorado realmente como una carrera más, con índices de productividad elaborados. Aunque la excelencia de una universidad depende mucho del doctorado, y sobre todo de la producción de doctores e investigadores, no logramos explicar algunas diferencias. La pauta es divergente pero todavía confusa. En las próximas décadas es posible que las universidades se decanten por modelos distintos, y entonces se podrán explicar las diferencias.

La Tabla 3 presenta el ranking de las 54 universidades españolas con relación a los seis indicadores fundamentales de cali$\mathrm{dad}$. Incluye como control los indicadores de desarrollo regional (PIB) y antigüedad de la universidad (ANT). Hay que notar que hay 54 universidades en todos ellos, salvo en los indicadores de títulos de doctor (TDE) en que hay cuatro universidades sin doctorado, y de forma similar el indicador de productividad (ETC) que se refiere solamente a 50 universidades. Para la Universidad de Burgos se realiza una estimación, pues carece de ese dato.

Para mayor claridad la Tabla 4 presenta las diez mejores universidades para cada uno de los seis indicadores de calidad. En la mitad de arriba están todas las universidades públicas y privadas (las privadas aparecen en cursiva). La mitad de abajo incluye sólo las universidades públicas, para las que existen datos más completos y válidos. La primera impresión es que las universidades privadas obtienen buenos resultados en cuatro de los seis indicadores: profesores, libros, profesoras, y productividad. Las universidades públicas ocupan los primeros diez puestos según el número de centros superiores; y todos menos el primero (en el que está la Universidad de Navarra) en títulos de doctor concedidos. En profesorado (PRO) seis universidades privadas están entre los diez primeros puestos ${ }^{5}$. En libros de biblioteca (LBE) hay cinco privadas de las diez. En mujeres profesoras hay cuatro universidades privadas entre los diez primeros puestos. En productividad de las carreras (ETC) hay cuatro de las seis universidades privadas que tienen datos. $\mathrm{Si}$ se tienen en cuenta las 54 universidades españolas, las universidades privadas - a pesar de ser solamente diez- ocupan posiciones muy elevadas en los indicadores de calidad.

Las universidades privadas ocupan el $33 \%$ de los diez-primeros-puestos en los seis indicadores, a pesar de que son muchas menos (varian entre el $12 \%$ y el $18 \%$ según los indicadores). La calidad general de las universidades privadas es clara, aunque el acceso de su alumnado está sesgado por el nivel económico familiar. Son universidades de pago, algunas bastante caras. El coste comparado con las públicas es de 5 a 15 veces más; pero terminan la carrera el doble de estudiantes, y en un período más corto. También hay diferencias ideológicas 


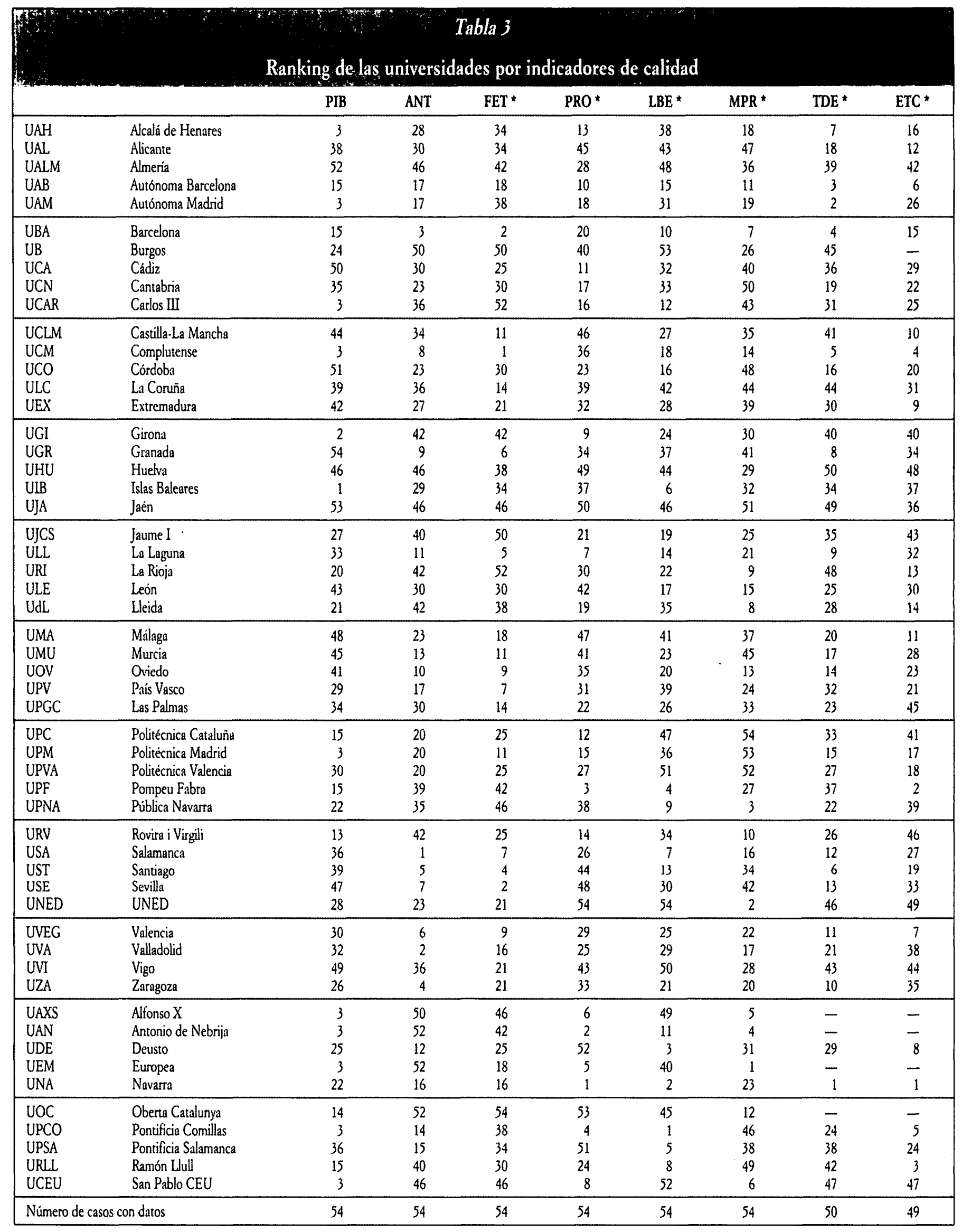




\section{Tabla 4}

Las diez mejores universidades españolas según seis indicadores de calidad

\begin{tabular}{|c|c|c|c|c|c|c|}
\hline \multicolumn{7}{|c|}{ Universidades privadas y públicas } \\
\hline$N$ & Centros (FET) & Profesores (PRO) & Libros (LBE) & Profesoras (MPR) & Tesis (TDE) & Productividad (ETC) \\
\hline $1 . "$ & Complutense & Navarna & Comillas & Europea & Navarra & Navarta \\
\hline $2 . n$ & Barcelona & Antonio de Nebrija & Navarra & UNED & Autónoma Madrid & Pompeu Fabra \\
\hline $3 . "$ & Sevilla & Pompeu Fabra & Dewsto & Pública Navarra & Autónoma Barcelona & Ramón Lull \\
\hline $4 . "$ & Santiago & Pontificia Comillas & Pompeu Fabra & Antonio de Nebrija & Barcelona & Complutense \\
\hline $5 . "$ & La Laguna & Europen de Madrid & Pontificia Salamanca & Alfonso $X$ & Complutense & Pontificia Comilles \\
\hline 6. & Grunada & Alforiso $X$ & Islas Baleares & San Pablo-CEU & Santiago & Autónoma Barcelona \\
\hline $7:^{\prime}$ & Salamanco & La Laguna & Salamanca & Barcelona & Alcalá de Henares & Valencia \\
\hline 8." & Pais Vasco & San Pabla-CEU & Ramón Lhull & Lleida & Granada & Detsto \\
\hline 9.1 & Valencia & Girona & Pública de Navarra & La Rioja & La Laguna & Extremadura \\
\hline $10 .^{n}$ & Oviedo & Autónoma Barcelona & Barcelona & Rovira i Virgili & Zaragoza & Castilla-La Mancha \\
\hline \multicolumn{7}{|c|}{ Universidades públicas } \\
\hline $10^{\prime \prime}$ & Complutense & Pompeu Fabra & Pompeu Fabra & UNED & Autónoma Madrid & Pompeu Fabra \\
\hline 2." & Barcelona & La Laguna & Islas Baleares & Pública Navarra & Autónoma Barcelona & Complutense \\
\hline 3. & Sevilla & Girona & Salamanca & Barcelona & Barcelona & Autónoma Barcelona \\
\hline 4. & Suntiago & Autónoma Barcelona & Pública Navarra & Lleida & Complutense & Valencia \\
\hline 5." & La Laguna & Cádiz & Barcelona & La Rioja & Santiago & Extremadura \\
\hline $6 "$ & Granada & Politécnica Cataluña & Carlos III & Rovira i Virgili & Alcalá de Henares & Castilla-La Mancha \\
\hline $7 .^{n}$ & SHlymanca & Alcalá de Henares & Suntiago & Autónoma Barcelona & Granada & Málaga \\
\hline s." & Pais Vasco & Rovira i Virgili & La Laguna & Oviedo & La Laguna & Alicante \\
\hline 9." & Vulencia & Politécnica Madrid & Autónoma Barcelona & Complutense & Zaragoza & La Rioja \\
\hline $10 .^{n}$ & Oviedo & Carlos III & Córdoba & León & Valencia & Lleida \\
\hline
\end{tabular}

Nota: En cursivas las universidades privadas.

que los indicadores no miden. El caso de la Universidad de Navarra es paradigmático, ocupando el primer puesto en tres indicadores (PRO, TDE y ETC) y el segundo en otro (LBE). En los otros dos indicadores (FET, MPR) no está entre los diez primeros puestos. También destaca bastante la Universidad Pontificia de Comillas. Por detrás aparecen las universidades públicas clásicas, como Complutense (de Madrid) y Universidad de Barcelona, junto a las autónomas. Pero los datos de las universidades privadas son a veces incompletos, o poco comparables. Es más fiable medir el nivel de estos seis indicadores de calidad en las 44 universidades públicas.

La misma tabla, en la mitad inferior presenta el ranking de las diez primeras universidades públicas para estos seis indicadores. Se puede medir el ranking en cada indicador (algo que se realiza en la investigación extensa). Aquí se observa las universidades que se sitúan globalmente entre los primeros (diez) puestos de los seis indicadores. La universidad que más aparece es Autónoma de Barcelona (cinco veces), aunque no es la primera en ningún indicador de calidad. Después están Barcelona y Complutense (cuatro veces). La Complutense está en primera posición en FET. La cuarta es Pompeu Fabra (que es una universidad pública en Barcelona) que aparece tres veces, pero en primera posición: en PRO, LBE, y ETC. Ya detrás están Autónoma de Madrid con una en primera posición (TDE), y Carlos III con dos, pero en posiciones más retrasadas dentro de las diez primeras universidades. Se observa que las universidades que más destacan son las clásicas, las autónomas y las emblemáticas. Pero todas están en las áreas metropolitanas de Madrid y Barcelona.

Entre Madrid y Barcelona hasta un $40 \%$ de posiciones en los seis indicadores (24 de los 60 posibles), cuando Madrid y Barcelona representan solamente el $23 \%$ de las universidades públicas españolas. Se nota más la excelencia de las universidades públicas barcelonesas, pues aparecen en el 22\% de las posiciones (cuando son el $9 \%$ de las universidades públicas). $\mathrm{Si}$ se tiene en cuenta todo Cataluña, representan el $30 \%$ de las universidades en las mejores posiciones, cuando las universidades catalanas son el $16 \%$ de las universidades públicas. Madrid parece bien representado con un $17 \%$ de universidades, un porcentaje menor al de Barcelona, pero hay más universidades públicas en Madrid (14\%). En cualquier caso, la posición alta en las escalas de calidad de Madrid y Barcelona es clara. Es parte de su éxito de estructurar las universidades en torno a un modelo múltiple de universidades, con cinco tipos básicos: clásica, autónoma, politécnica, nueva-emblemática y a distancia. Estos cinco tipos de universidades utilizan estrategias distintas pero consiguen buenos puestos en los rankings de calidad. La excepción son las universidades a distancia (UNED en Madrid y UOC en Barcelona) que no destacan en casi ninguna variable. Solamente UNED consigue el primer puesto en 
mujeres profesoras (MPR), que es el indicador de los seis fundamentales que menos impacto parece tener en la calidad global de las universidades. UOC no aparece en ninguno de los diez primeros puestos. Carlos III aparece solamente en dos: en posición sexta (en LBE) y décima (en PRO).

Las demás universidades que destacan son fundamentalmente clásicas: Sevilla, Santiago, La Laguna, Granada, Salamanca, Valencia, Oviedo y Zaragoza. Algunas universidades destacan por motivos concretos: Cádiz por profesorado; Islas Baleares y Pública de Navarra por bibliotecas; o bien Extremadura o Castilla-La Mancha, por productividad de sus carreras. Las universidades en los mejores puestos de mujeres profesoras (MPR) no son las usuales, empezando porque la que más destaca es UNED. La lista de las diez mejores incluye cuatro universidades catalanas (que en este indicador también aparecen más desarrolladas), además de Pública de Navarra, La Rioja y León. Es, pues, un indicador que en la distribución de las «mejores universidades» es también diferente, aunque incluye Barcelona (en el tercer puesto) y Complutense (en el noveno). La distribución de las mejores universidades en los seis indicadores de calidad demuestra que las mejores universidades españolas son las de Madrid y Barcelona, las clásicas, y en general las catalanas por encima de otras. Estos tres tipos no tienen rival en el contexto general de universidades públicas de excelencia. La universidad del País Vasco sólo aparece una vez en el ranking (en la 8. ${ }^{a}$ posición de FET). Las politécnicas - frente a la visión popular de que son universidades de gran calidad- sólo destacan algo en profesorado (dos de ellas, no Politécnica de Valencia). Una universidad que no se suele pensar como de calidad es La Laguna, en Canarias, universidad clásica (creada en 1701), con bastantes buenas posiciones en cuatro indicadores. En cualquier caso el centralismo -madrileño y barcelonés- del sistema universitario público español es todavía una situación evidente, no sólo en cuanto a universidades (tienen $39 \%$ de todas las universidades españolas, y $23 \%$ de las universidades públicas), sino en cuanto al porcentaje de estudiantes (36\% estudiantes totales y $6,5 \%$ de los privados). Es, pues, un centralismo metropolitano de cantidad y también de calidad. Sólo el sistema privado de las universidades de Navarra (en Pam. plona) y de Deusto (en Bilbao) logra reequilibrar ese centralismo metropolitano.

\section{Cinco índices de calidad}

Los seis indicadores de calidad se pueden combinar para lograr un índice único. Los seis indicadores de calidad de las universidades españolas son: FET, PRO, LBE, MPR, TDE, y ETC. El índice de calidad más simple es el sumatorio de estos seis indicadores. Supone una cantidad global de 124, de acuerdo con los valores medios para España de los seis indicadores: $10+5,4+14+33+3,8+58$. Dado que son seis indicadores, este sumatorio podría dividirse por 6 , y llegar a una puntuación de 21 como media de todas las universidades españolas (exactamente 20,6 puntos). Éste es el que se denomina índice sumatorio, de acuerdo pues con la fórmula sencilla:

$$
\begin{aligned}
\text { Índice sumatorio } & =(\mathrm{FET}+\mathrm{PRO}+\mathrm{LBE}+\mathrm{MPR}+ \\
& +\mathrm{TDE}+\mathrm{ETC}) / 6
\end{aligned}
$$

Este índice tiene una utilidad limitada, pues no da pesos ponderados a los indicadores. Se basa en cantidades que, como corresponden a tasas, tienen medias y varianzas bastante diferentes. Si no se quiere ponderar ninguno de los seis indicadores pero se desean nivelar las medias, se ofrece un índice combinado que los hace más similares. Así, se multiplica FET por 2, PRO por 10, LBE por 2, y TDE por 10, dejando iguales MPR y ETC. Se obtienen, así, cantidades medias mucho más similares: $20,54,28,33,38$ y 58 . Con ello los seis indicadores se tienen en cuenta de forma similar en una fórmula que los reúne a los seis. El sumatorio es 231 que si se divide por 6 (el número de indicadores) es 38,4 . Si a su vez se divide por 10 da una media de 3,84 similar a lo que sería un GPA (grande point average), salvo que no tiene una conexión con ese sistema de notas. La nota máxima de este segundo índice llega casi a diez (9,26 en el caso de la Universidad de Navarra) y la mínima puede ser muy baja: 1,55 UNED y 2,13 de Oberta de Catalunya. Este indice combinado sigue la fórmula siguiente: Índice combinado $=(\mathrm{FET} \times 2+\mathrm{PRO} \times 10+\mathrm{LBE} \times 2+$ $+\mathrm{MPR}+\mathrm{TDE} \times 10+\mathrm{ETC}) / 60$

Este índice favorece un poco más a los indicadores con número medio más alto, es decir, la tasa de profesorado (PRO) y la de productividad (ETC); ambos son importantes. Tiene algo menos en cuenta indicadores como FET (número de centros superiores) o LBE (libros de biblioteca por estudiante) que son también menos centrales en la medición global de la calidad. Puede argumentarse que las tres universidades politécnicas (de Madrid, Cataluña y Valencia), y además Alfonso X el Sabio, tienen una puntuación final baja en este índice, porque el indicador de libros de biblioteca favorece a las universidades humanistas (y sociales) desfavoreciendo a las de ciencias y sobre todo a las tecnológicas. Sin embargo, obtienen puntuaciones entre 3 y 4. Para modificar un poco esta desigualdad se propone un índice más técnico, en que el único cambio es que el peso del indicador LBE no se multiplica por ningún factor de ponderación. La fórmula de este índice técnico es la siguiente:

Índice técnico $=(\mathrm{FET} \times 2+\mathrm{PRO} \times 10+\mathrm{LBE}+\mathrm{MPR}+$ + TDE $\times 10+$ ETC) $/ 60$ 
Este índice alcanza un valor medio de 3,61, que es muy parecido al índice combinado, pero dando menos importancia a las bibliotecas. Oscila entre 8,56 y 1,52, cubriendo bien lo que sería una nota tradicional (española) con el máximo de diez. Las variaciones son muy grandes en las universidades privadas debido a que faltan algunos datos concretos en varias de esas universidades. El análisis de índice global podría aplicarse mejor a las 44 universidades públicas.

Los dos índices siguientes tienen en cuenta -en principioúnicamente a las universidades públicas, que tienen los datos completos. Por un lado, conviene recuperar la importancia de las bibliotecas (LBE ponderado por un factor doble), dado que su reducción en el índice técnico no logra que las universidades politécnicas mejoren mucho. El indicador de mujeres profesoras parece excesivamente alto (33) y algo desconectado de los otros cinco indicadores de calidad. Se decide, pues, darle un valor menor, exactamente la mitad: MPR/2. Los seis indicadores ponderados se dividen entre 40 para establecer el índice en unos extremos más manejables, como si fuera una puntuación sobre 10, a la que se está más acostumbrado. El indice integral sigue, pues, la siguiente fórmula:

Índice integral $=($ FET $\times 2+\mathrm{PRO} \times 10+\mathrm{LBE} \times 2+$ $+\mathrm{MPR} / 2+\mathrm{TDE} \times 10+\mathrm{ETC} / 40$

La media es de 5,80, con extremos que van desde 7,97 (Pomepu Fabra) hasta 1,80 (UNED). Si se estudia la distribución de universidades y de indicadores, se nota que el indicador de tesis doctorales (TDE) —que es uno de los importantes para definir lo que modernamente se entiende como «universidad investigadora»- aparece con un peso relativamente bajo. Por eso se sugiere la posibilidad de darle un peso mayor, quizás multiplicándolo por 15 en vez de por 10 . Con ello se logra que haya tres indicadores más importantes, y relativamente iguales en las medias: profesores PRO (con un valor 54), títulos de doctor TDE (valor 57) y productividad de las carreras ETC (58). El indicador de libros LBE mantiene un valor aproximadamente la mitad (28) de los otros tres indicadores más básicos, así como el de centros superiores FET (20). Al indicador que se le da menos peso es el de mujeres profesoras MPR (16). La fórmula que se aplica para el indice investigador es la siguiente:

$$
\text { Índice investigador }=(\mathrm{FET} \times 2+\mathrm{PRO} \times 10+\mathrm{LBE} \times 2+
$$$$
+\mathrm{MPR} / 2+\mathrm{TDE} \times 15+\mathrm{ETC}) / 40
$$

El resultado medio de las universidades públicas españolas es 6,25, es decir, que simbólicamente aprueban más de la mitad. El máximo corresponde a Universidad Autónoma de Barcelona, con una puntuación de 8,50 (es decir, práctica. mente «sobresaliente») y el mínimo corresponde a UNED con una nota de 1,90 . Tanto la variabilidad como las notas extremas se ajustan bien a la finalidad de un índice de calidad universitaria.
En la Tabla 5 se incluyen los cinco índices, junto con la nota de cada universidad, así como el puesto que ocupa cada universidad. Se considera que los índices son progresivamente mejores, es decir, que el indice investigador es seguramente el mejor, pues va incorporando los cambios con arreglo al funcionamiento de los índices previos. Así, el indice sumatorio es una mera adición de los seis indicadores de calidad, pero sin corregir el tamaño diferente de las tasas. Este sumatorio se perfecciona en el índice combinado, que es el primero que pondera los indicadores. A partir de ahí se mantiene una ponderación básica, y se van realizando cambios pequeños en algún indicador concreto, para nivelar más su valor medio y la idea de excelencia que se propone.

El índice técnico podría ser el más ajustado utilizando todas las universidades privadas y públicas, aunque favorece levemente a las universidades politécnicas, y quizás da demasiada importancia al proceso de feminización. Las universidades privadas se reparten los puestos con las públicas a lo largo de todo el ranking ocupando los dos primeros puestos, y el penúltimo, con algunos puestos intermedios. Se comprueba así la dispersión alta de valores en enseñanza privada, por lo que no puede hablarse de una pauta determinada, ni de una calidad superior de la enseñanza privada, sino de instituciones concretas.

El índice integral que está diseñado para universidades públicas, es ya bastante válido. Parece dar una importancia limitada al factor de doctorado e investigación, que define la calidad investigadora de una universidad. A pesar de ello, las politécnicas quedan bastante en la media, destacando sólo Politécnica de Madrid un poco por encima. El mejor de todos los índices se considera el indice investigador, que tiene algo más en cuenta la productividad del tercer ciclo, que es la variable diferenciadora entre «universidad» y «universidad investigadora». El proceso de feminización se sigue teniendo en cuenta pero de forma un poco más limitada. Este índice es el que se propone como más avanzado para medir la calidad de las universidades españolas.

\section{Ranking de las universidades públicas}

El objetivo es entender y medir los aspectos diversos de la calidad de las universidades españolas definiendo operativamente el concepto de excelencia universitaria. Pero la meta del análisis es también ofrecer un índice final que mida diferencialmente los niveles globales de calidad de las universidades 


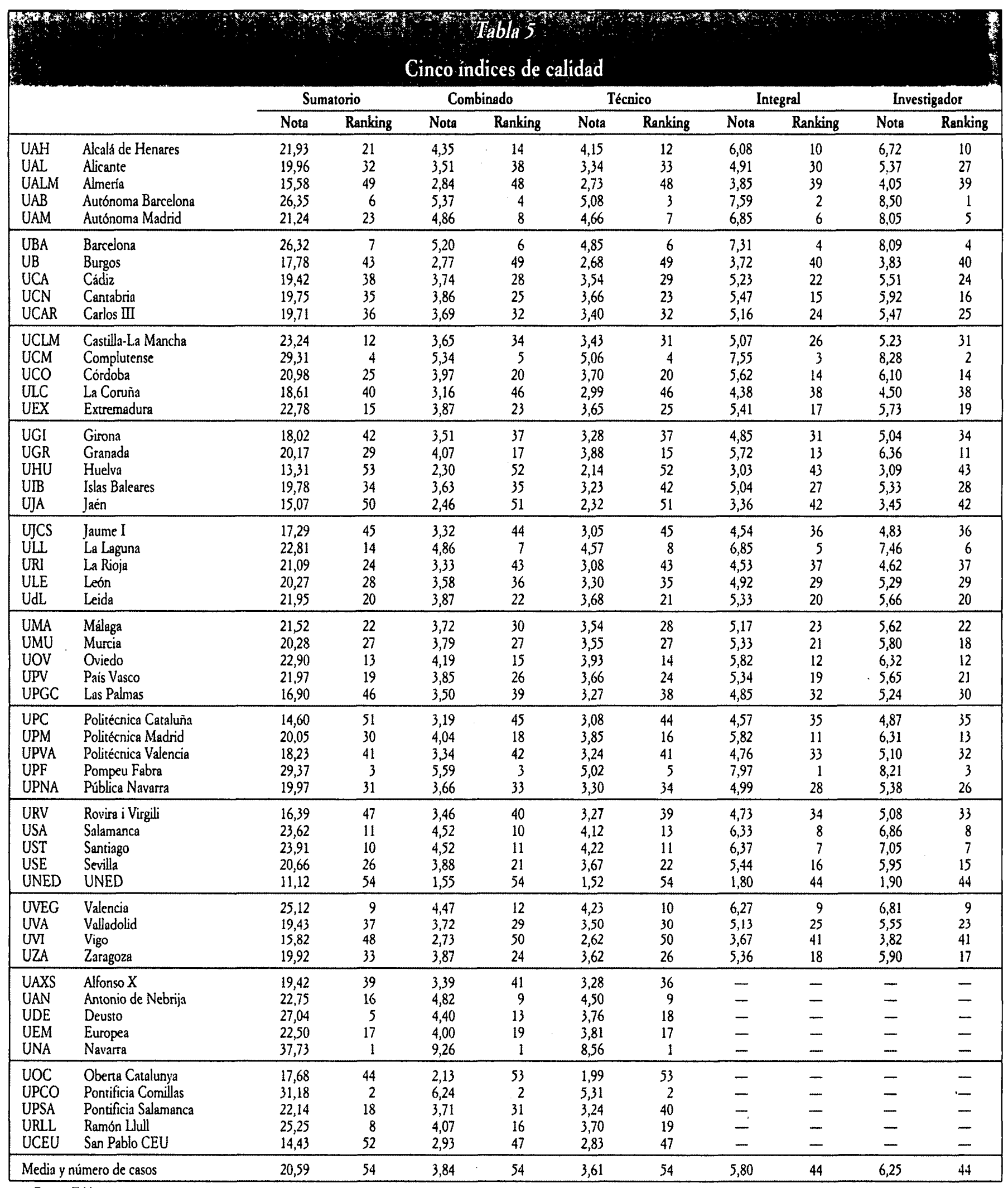

Fuente: Tabla 1.
Notas: Al efectuar las fómulas se ha tomado la decisión de sustituir los datos missing de TDE por 0 , y los de ETC por la media de las universidades que es 58,3 .

Aplicación de las fórmulas:

Sumatorio: (FET + PRO + LBE + MPR + TDE + ETC)/6

Combinado: (FET*2+PRO*10+ $\left.{ }^{*}+\mathrm{LBE}^{*} 2+\mathrm{MPR}+\mathrm{TDE} * 10+\mathrm{ETC}\right) / 60$

Técnico: (FET $* 2+$ PRO $* 10+\mathrm{LBE}+\mathrm{MPR}+\mathrm{TDE} * 10+\mathrm{ETC}) / 60$

En el resto de fórmulas se incluye sólo las 44 universidades públicas:

Integral: $(\mathrm{FET} * 2+\mathrm{PRO} * 10+\mathrm{LBE} * 2+\mathrm{MPR} / 2+\mathrm{TDE} * 10+\mathrm{ETC}) / 40$

Investigador: $(\mathrm{FET} * 2+\mathrm{PRO} * 10+\mathrm{LBE} * 2+\mathrm{MPR} / 2+\mathrm{TDE} * 15+\mathrm{ETC}) / 40$ 
en España. La Tabla 6 ordena las universidades públicas espanolas de acuerdo con una nota global sobre su calidad. Combina los seis indicadores de calidad descritos y analizados utilizando el indice investigador. La tabla muestra arriba las diez primeras universidades según su calidad, y en la parte de abajo las que no alcanzan el listón simbólico del cinco. Entre las diez primeras hay tres universidades barcelonesas (Autónoma de Barcelona, Pompeu Fabra, y Barcelona) y tres madrileñas (Complutense, Autónoma de Madrid, y Alcalá de Henares). Junto a estas seis excelentes universidades metropolitanas, en el grupo de las-diez-mejores están cuatro universidades clásicas en España: La Laguna, Santiago, Salamanca, y Valencia. Este resultado del ranking no debe producir ninguna sorpresa. Están las universidades que vox populi se consideran como las mejores. La rivalidad Madrid-Barcelona es evidente, y refleja también la realidad social española. Barcelona se sitúa un poco por delante.

El lugar exacto que ocupa cada universidad a menudo depende, como las notas, de variaciones de décimas o incluso centésimas, por lo que no debe ser tenido demasiado en cuenta. Lo lógico sería dar la nota con sólo un decimal, pero conservando el orden obtenido. La universidad número uno es la Universitat Autònoma de Barcelona. Es una universidad que no destaca demasiado en ningún indicador, pero que mantiene unas posiciones avanzadas en todos ellos. Le faltaría tener más centros, y quizás una productividad un poco mayor de las carre. ras, para destacar aún más en la puntuación final. Es una muestra de cómo las universidades «autónomas», que fueron creadas por la dictadura franquista en el año mítico de 1968, consiguieron un nivel elevado de calidad y alguna de ellas ha sabido mantener este nivel diferencial alto. Seguramente no es una universidad de moda, ni se suele conocer como la mejor, pero los indicadores de calidad, y sobre todo el índice investigador, le adjudican una excelencia alta.

El número dos es la Complutense, una universidad grande y masificada, pero que es la Meca de los mejores profesores y catedráticos españoles. Es una universidad extensa, con todas las ramas del saber, que tiene muchos profesores y la primera biblioteca universitaria de España (con 2,1 millones de volúmenes). Algunos de sus profesores son los mejores del país. Pero dada su extensión no destaca tanto en número de pro. fesores ni en libros por estudiante. Relativamente tiene bastantes profesoras-mujeres y una alta productividad. Es una universidad excelente que, como la Autónoma de Barcelona, su calidad no puede medirse por un único indicador, sino por la combinación adecuada de los seis. En cualquier ranking es una universidad que está entre los primeros cinco puestos.

La tercera es Pompeu Fabra, que es una universidad catalana, pública, especial. Se crea en la última década del siglo XX (en el año 1990) con la decisión temprana de convertirse en una universidad de calidad, para pocos y buenos alumnos. Con

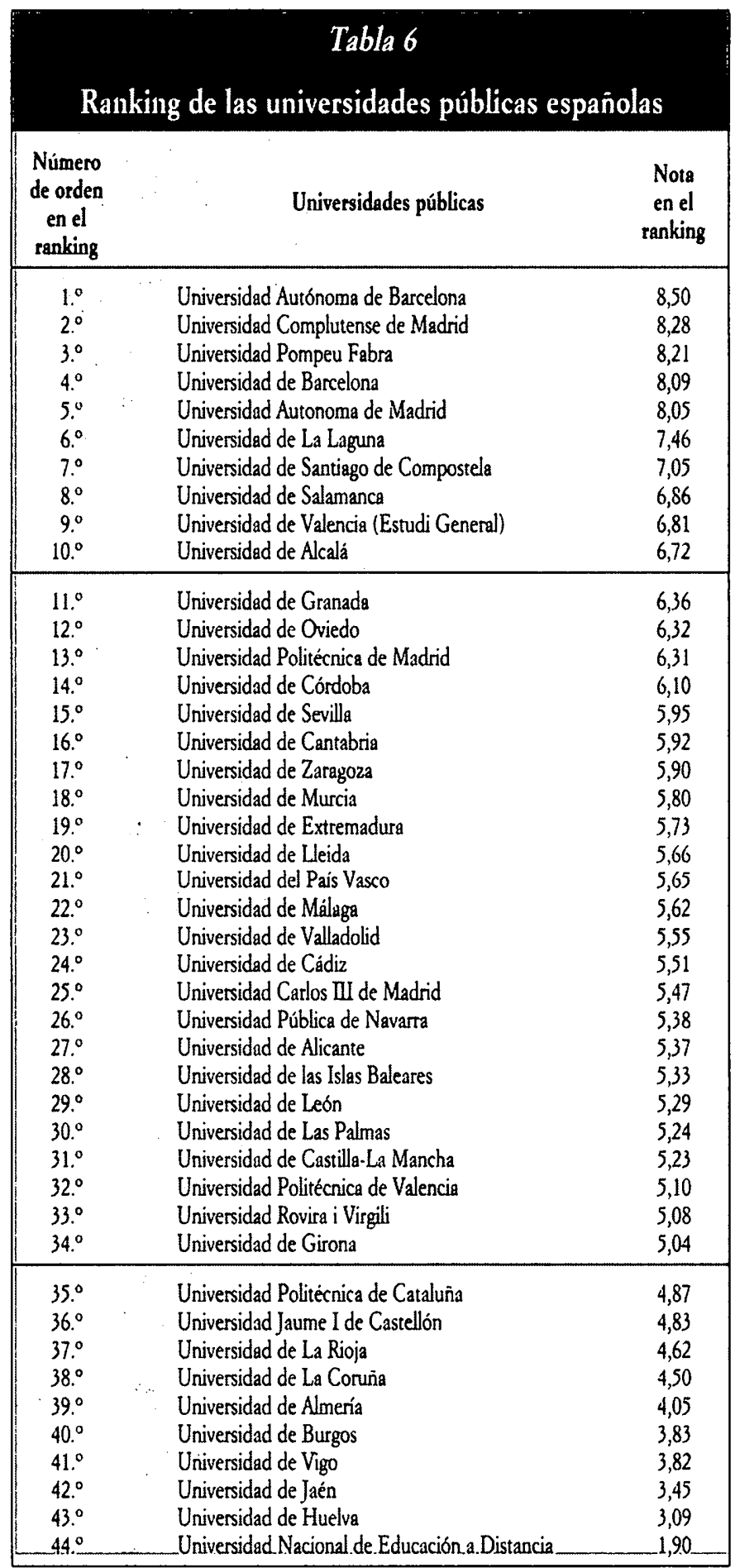

Nota: La fórmula uilizada es:

$(\mathrm{FET} \times 2+\mathrm{PRO} \times 10+\mathrm{LBE} \times 2+\mathrm{MPR} / 2+\mathrm{TDE} \times 15+\mathrm{ETC}) / 40$

el tiempo se dedica sobre todo a alumnas. Tiene muchos recursos de profesores, siendo la universidad española con más profesores. Ha dedicado enormes esfuerzos a construir en poco tiempo una biblioteca de buen tamaño, sobre todo para el número de estudiantes de la universidad actual (más de un cuarto de millón de volúmenes, muchos de ellos en inglés). 
Tiene una excelente productividad en sus carreras, los/as estudiantes estudian a tiempo completo, obtienen buenas notas, y van sacando los cursos completos. En toda Cataluña mantiene las notas-de-corte de selectividad más altas para poder matricularse. Es una universidad edificada en el downtown de Barcelona, en varias zonas en decadencia, cerca del «barrio chino», o al lado del zoológico. Atrae un estudiantado con muy buenas notas, femenino, seguramente de clase más alta que otras universidades públicas. Su tercera posición en el ranking, a pesar de la juventud de la universidad, es un logro considerable. Habrá que ver cómo envejece esta universidad. Si sigue el modelo de las autónomas (en Madrid y sobre todo Barcelona) es posible que mantenga posiciones buenas. La población -e incluso el profesorado universitario español- suele comparar Pompeu Fabra en Barcelona con Carlos III en Madrid, considerándolas casi al mismo nivel, como universidades nuevas, con muchos recursos, pequeñas, en zonas urbanas deprimidas, más «americanizadas». Sin embargo, Carlos III no destaca en casi ningún indicador de calidad. Pompeu y Carlos III tienen sólo en común que han contratado bastante profesorado, y que invierten bastante en biblioteca, aunque algo menos la Carlos III, a pesar de ser un año más antigua (no llega a los doscientos mil volúmenes). Carlos III ocupa el puesto $25^{\circ}$ en el ranking, con una nota final del índice de 5,5. No es, pues, comparable a Pompeu Fabra (índice de 8,2), aunque la intención de sus creadores era muy similar.

Le sigue, en el cuarto puesto del ranking, la Universidad de Barcelona. Es una universidad muy parecida a la Complutense, es decir, vieja y extensa, modelo de universidades omnicomprensivas. Relativamente le falta profesorado, pero para compensar tiene una excelente biblioteca de 1,5 millones de volúmenes. Es la tercera universidad con mujeres-profesoras, cosa que contribuye (levemente) a alcanzar un nivel alto en el ranking. Está muy bien de doctorado y también de productividad en las carreras. Es, pues, una universidad excelente según todos los indicadores, incluyendo el ser diversa y no discriminante.

Detrás, en el puesto quinto, está la Autónoma de Madrid. Las dos autónomas (Barcelona y Madrid) fueron creadas en el año histórico de 1968, por el franquismo, no sólo con la intención de que fueran universidades de calidad, más pequeñas que «las centrales» Complutense y Barcelona, sino además lejos de la gran ciudad para evitar manifestaciones, cortes de tráfico urbano, y problemas estudiantiles. Autónoma de Barcelona fue creada en el bosque de Bellaterra, y Autónoma de Madrid en Cantoblanco. Durante los primeros años fueron universidades pequeñas, con un profesorado más joven, a menudo prometedor. Las clases eran más pequeñas, el profesorado más dedicado, todo menos politizado. Construyeron pronto bibliotecas relativamente extensas ( 676.000 volúmenes Autónoma de Barcelona y 444.000 Autónoma de Madrid). Renovaron los pro- gramas de estudio, y pusieron en marcha sistemas de evaluación de la docencia. Se dedicaron bastante a la investigación. Con el paso del tiempo se han convertido en universidades bastante grandes, cercanas a los 40.000 estudiantes (un poco menor la Autónoma de Madrid). Pero años después conservan todavía algunas de las cualidades que hacen que una universidad sea de calidad. La Autónoma de Madrid ha sufrido quizás más el paso del tiempo, se ha rutinizado algo, ha dejado de comprar libros para la biblioteca, y su profesorado se ha politizado (se ha dedicado a otros cargos) o ha perdido el brillo de la ilusión inicial. «Ha sido una gran desilusión», nos cuenta uno de sus catedráticos. Por eso el índice de Autónoma de Madrid $(8,0)$ está por debajo de Autónoma de Barcelona $(8,5)$, pero en cual. quier caso es una universidad excelente.

La Laguna —en el pueblo de San Cristóbal de La Laguna-, en la isla de Santa Cruz de Tenerife, es una universidad muy buena, cuya excelencia es poco conocida en la península. Aparte de las universidades metropolitanas (de Madrid y Barcelona) es la universidad que más aparece en los puestos altos de los indicadores. Es muy buena en número de centros superiores, y sobre todo en tasa de profesorado. En contra del mito de que los profesores no quieren residir en Canarias, resulta que tiene el segundo puesto de España en tasa de profesorado $(8,4)$ sólo por detrás de Pompeu Fabra $(11,4)$. La Laguna está regular de bibliotecas (440.000 ejemplares), no tiene muchas profesoras, pero su actividad de doctorado es muy buena. La combinación de los factores produce que sea una universidad de excelencia.

Las tres universidades restantes que están entre las ten top son todas universidades clásicas: Santiago, Salamanca y Valencia. Están entre las seis universidades más antiguas de España. Eso demuestra que la antigüedad no es un mérito, pero que ayuda a cristalizar una organización universitaria sólida, con recursos de buena calidad y excelencia. Las tres no sólo imparten bien la docencia, sino que se especializan en investigación. Tienen muchos centros, y en ese sentido son muy universitas. Están algo masificadas y les falta algo de profesorado. Salamanca y Santiago tienen bibliotecas buenas. Ninguna tiene mucho profesorado femenino, lo que les desfavorece mostrándose como universidades un poco tradicionales. Santiago y Valencia están muy bien en la producción de títulos de doctor. Valencia destaca por su productividad. Tienen niveles buenos en varios indicadores, explicando así su posición en el ranking final en el «club de las diez mejores universidades públicas». Las tres tienen seguramente problemas de masificación, y son algo tradicionales.

La décima universidad, de Alcalá de Henares, es un añadido de universidad pública que no tiene correlativo en Cataluna. Es una universidad buena, bastante por delante de la supues. tamente emblemática de Carlos III. Situada a 50 kilómetros de Madrid, tiene un tamaño interesante (21.000 estudiantes), 
con una biblioteca relativamente baja para los niveles españoles (un cuarto de millón de volúmenes) y un rector magnífico que ha sabido desarrollar la universidad y mantener una buena calidad. Es excelente en doctorado (la sexta de España), y está bien de profesorado y de productividad. Pero necesita desarrollar mucho su biblioteca. Se beneficia al mismo tiempo de estar cerca y lejos de Madrid. Si se compara esta décima universidad (índice 6,7 puntos) con la primera, que es Autónoma de Barcelona (índice 8,5), las diferencias en el índice son del $26 \%$.

Hay que explicar por qué las universidades politécnicas están en una posición tan baja en el ranking final: en el puesto $13^{\circ}$ la Politécnica de Madrid, en el $32^{\circ}$ la Politécnica de Valencia, y $35^{\circ}$ la Politécnica de Cataluña. En realidad la Universidad Politécnica de Madrid está en buena posición, con un índice de 6,3 puntos. Las tres son popularmente conocidas como universidades buenas, exigentes (suspenden muchos estudiantes), con mucho profesorado. Sin embargo, no destacan mucho en ninguno de los indicadores de calidad. Su puesto en el ranking de cada indicador es el siguiente:

\begin{tabular}{|lrrrrrrrr|}
\hline & \multicolumn{6}{c|}{ Puestos en el ranking } \\
\cline { 2 - 8 } & Indice investigador & FET & PRO & LBE & MPR & TDE & ETC \\
\hline Politénica de Madrid & 11 & 15 & 36 & 53 & 15 & 17 & $130^{\circ}$ \\
Politécnica de Valencia & 25 & 27 & 51 & 52 & 27 & 18 & $320^{\circ}$ \\
Politécnica de Cattaluña & 25 & 12 & 47 & 54 & 33 & 41 & $30^{\circ}$ \\
Alfonso X el Sabio & 46 & 6 & 49 & 5 & - & - & $30^{\circ}$ \\
\hline
\end{tabular}

En esta tabla se añade la universidad privada Alfonso $\mathrm{X}$ el Sabio, pues tiene también bastante enseñanza politécnica, aunque no lleva la etiqueta de «politécnica» en el nombre. El indice referido a Alfonso X es el «índice técnico» (sobre 54 universidades, mientras que el otro índice investigador es sobre 44). Pero incluso si se aplica el índice técnico a las otras tres su posición no varía mucho: $16^{\circ}, 41^{\circ}$ y $44^{\circ}$ respectivamente (Madrid, Valencia, Cataluña). Como se observa, los puestos en los rankings de los seis indicadores no son nada favorables a las universidades politécnicas. La Politécnica de Madrid es la más extensa; con 50.000 estudiantes y más carreras que las otras. En profesorado están relativamente bien las politécnicas - sobre todo la Politécnica de Madrid-, siendo el factor en que más destacan, pero sin llegar a estar entre las diez primeras. En bibliotecas están bastante mal, aunque sea en edificios diseñados como «biblioteca inteligente». En profesorado femenino mantienen las tasas mínimas de España, aunque en el índice es el indicador que menos peso se le ha dado. Son tradicionalmente universidades de varones para varones. Salvo la Politécnica de Madrid, dedican poco esfuerzo al doctorado, que seguramente consiste en un servicio endogámico para su propio profesorado. Su productividad es baja, sobre todo en la Poli- técnica de Cataluña, que tiene fama de suspender mucho; y lo hace. Lógicamente, con esos indicadores es imposible obtener un buen nivel en el ranking de calidad. La universidad privada más politécnica - la de Alfonso X el Sabio- es una universidad nueva, reducida, con una biblioteca reducidísima (20.000 volúmenes para una «universidad» es llamativo) y sin doctorado.

Las universidades politécnicas tienen fama de excelencia, pero no es posible mantener esa hipótesis con los indicadores de calidad. No son universidades extensas en número de carreras, tienen bibliotecas pequeñas aunque no las consideren tan necesarias, son universidades masculinas, dedican poco esfuerzo al doctorado, y sus indicadores de productividad son bajos. La Politécnica de Cataluña ocupa un puesto bajo no tanto por otros indicadores de calidad como porque suspende mucho, hay bastantes repetidores, y poquísimos estudiantes terminan la carrera en los años previstos. De ahí quizás la fama equivocada de que es una universidad buena, en la visión tradicional -absurda - de que una universidad «buena» es la que suspende mucho, y apenas crea investigadores o doctores. En cualquier caso sus estudiantes obtienen empleos en el mercado laboral.

El sistema universitario catalán es bueno, un poco mejor que el madrileño, y bastante mejor que el del País Vasco. La universidad del País Vasco sólo alcanza el puesto $21^{\circ}$, bastante por debajo de su universidad privada competidora Deusto (que tiene matriculados a uno de cada cinco estudiantes del País Vasco). Efectivamente, Cataluña tiene tres universidades entre las diez mejores universidades: Autónoma de Barcelona (la primera), la relativamente nueva Pompeu Fabra (la tercera), y la Universidad de Barcelona (cuarta). Para equilibrar la situación la Politécnica de Cataluña ocupa un puesto bajo en el ranking $\left(35^{\circ}\right)$. Las otras tres universidades provinciales creadas en el año olímpico de 1992 no logran todavía un puesto demasiado alto. La mejor es Lleida, que ocupa el puesto $20^{\circ}$. Luego a cierta distancia está Rovira i Virgili (en Tarragona) en el puesto $33^{\circ}$, por encima de Girona (puesto $34^{\circ}$ ). Cataluña mantiene, pues, un sistema dicotómico, con universidades provinciales que no son muy buenas, y con universidades excelentes en la ciudad de Barcelona, atrayendo estudiantes de la provincia de Barcelona e incluso de las otras provincias. Universitat Oberta de Catalunya (UOC) es, según los índices (por ejemplo, el índice técnico), la penúltima universidad de España. Las universidades a distancia aparecen en posiciones muy bajas según los indicadores utilizados: $53^{\mathrm{a}}$ y $54^{\mathrm{a}}$. UOC es además una universidad privada, pero con objetivos supuestos de universidad pública, todavía una cierta confusión en su modelo (a distancia o virtual), pocos estudiantes, y medios limitados.

Madrid tiene también tres universidades en los diez primeros puestos: Complutense, que es la segunda mejor universidad de España, Autónoma de Madrid, en el quinto puesto, y Alcalá de Henares, en el puesto décimo. Pero después de las ten top, 
Madrid tiene una universidad muy bien situada, Politécnica de Madrid (en el puesto $13^{\circ}$ ), que es algo más que una politécnica en sentido estricto. Carlos III, en el sur de Madrid, con 11.000 estudiantes, ocupa solamente el puesto $25^{\circ} \mathrm{UNED}$, por ser universidad a distancia, ocupa el último puesto de la lista $\left(44^{\circ}\right)$. UNED es una universidad que en los seis indicadores de calidad fundamentales sólo destaca por ser la universidad con más mujeres profesoras (después de la primera, que es la Universidad Europea de Madrid). No hay ningún otro indicador en que destaque. Aunque para ser a distancia tiene una biblioteca de casi 210.000 ejemplares, y un acceso más que nominal a los 2,1 millones de la Complutense.

Junto con UNED, que es a distancia, y la Universidad Politécnica de Cataluña, que es la más estricta de las politécnicas, las otras universidades que no alcanzan el listón mínimo del «cinco» son bastante recientes. La Coruña y Vigo son de 1989; pero la mayoría son de los años noventa, como Jaume I de Castellón que es de 1991, La Rioja de 1992, Almería, Jaén y Huelva de 1993, y Burgos de 1994. Estas universidades no han tenido tiempo de desarrollar carreras ni de completar doctorados, por lo que su posición en el ranking, aun siendo justa es justificable. Es importante seguir su evolución en las próximas décadas cuando seguramente se van a ir diferenciando.

Andalucía tiene ocho universidades - una por provincia-, ya que ésa ha sido la política universitaria del gobierno autónomo andaluz. La mejor desde luego es la de Granada (la $11^{\circ}$ ), una universidad extensa y con solera, creada en el año 1531. Sevilla (creada veintiséis años antes) ocupa el puesto $15^{\circ}$, que es relativamente alto. Málaga es la $22^{\mathrm{a}}$ y Cádiz la $24^{\mathrm{a}}$ Las tres más nuevas, todas creadas en 1993, ocupan puestos muy bajos: Almería el $39^{\circ}$, Jaén $42^{\circ}$ y Huelva el penúltimo (43..$^{\circ}$. En el ranking andaluz Córdoba aparece descolocada, bastante arriba (la $14^{\mathrm{a}}$ ). Tiene algunas carreras como Veterinaria y la de Ingenieros Agrónomos que son bastante buenas. Andalucía presenta un modelo de universidades públicas dicotómico, con universidades bastante buenas, sobre todo Granada una de las de más tradición en España. En una posición retrasada en el ranking están Málaga y Cádiz, y hacia el furgón de cola Almería, Jaén y Huelva.

El análisis detallado del ranking de todos los indicadores puede explicar la posición relativa de cada una de las universidades. A algunas personas puede sorprenderles la buena posición de la universidad de Oviedo en el $12^{\circ}$ puesto (es en realidad la universidad de todo el Principado de Asturias, sin competición privada), pero hay que tener en cuenta que es una universidad con solera, creada en el año 1604 y que destaca en varios indicadores, sobre todo en número de centros y profesoras. La de Córdoba presenta una posición alta $\left(14^{a}\right)$, quizás debido a que está bien de libros por estudiante, y también de productividad. La universidad de Sevilla está también en un puesto relativamente alto $\left(15^{\circ}\right)$. País Vasco está en un puesto demasiado bajo $\left(21^{\circ}\right)$ que no debe ser ajeno a los problemas sociales y políticos de esa Comunidad Autónoma, junto al hecho de que una de las mejores universidades privadas (Deusto) está en la misma ciudad de Bilbao enfrente del Museo Guggenheim. En el indice técnico Deusto es la $18^{\mathrm{a}}$ y la Universidad del País Vasco la $24^{\text {a }}$. La Pública de Navarra compite con la privada universidad de Navarra no sólo por el nombre, sino también por los/as estudiantes mejores y los recursos de investigación de la Comunidad Autónoma. Pero no puede evitar que sea la privada la que concentre el $59 \%$ de los estudiantes en Pamplona. La Pública de Navarra ocupa solamente el puesto $26^{\circ}$, moderadamente abajo del ranking. En el índice técnico Navarra (privada) es la primera y la Universidad Pública de Navarra es la $34^{a}$. En la competición dentro de Canarias, la de La Laguna mantiene unos niveles muy altos de calidad (es la sexta universidad de España), mientras que la de Las Palmas roza el aprobado (puesto $30^{\circ}$ ).

La dicotomía universidad privada/pública no es tan clara. En un orden de calidad completo, que incluya ambos tipos de universidades en España, las privadas aparecen a todo lo largo del ranking. En el indice técnico (el más perfecto que incluye a todas las universidades de España) los dos primeros puestos están ocupados por dos universidades privadas: Navarra (con 8,56 puntos) y Pontificia de Comillas (con 5,31). Aunque las dos están en los primeros puestos hay que notar la distancia que existe entre la primera - Navarra-y la segunda (61\% más de puntuación). En una cierta posición aventajada aparece también Antonio de Nebrija (en el puesto $9^{\circ}$ de índice técnico), que no es conocida como una universidad buena, sino más bien tecnológica. Luego hay tres universidades privadas juntas en la mitad de arriba del ranking ocupando las posiciones $17^{\mathrm{a}}$ a $19^{\mathrm{a}}$ : Europea de Madrid, Deusto y Ramón Llull. La Universidad Europea de Madrid está en buena posición, dada su juventud, sobre todo si se compara con la centenaria Deusto, a la que precede. En la mitad inferior del ranking están Alfonso X $\left(36^{\mathrm{a}}\right)$ y Pontificia de Salamanca $\left(400^{a}\right)$. Otras dos están situadas en el grupo inferior del ranking: San Pablo (en el puesto $47^{\circ}$ de 54 universidades), y la Oberta de Catalunya (es la penúltima), pero cuya posición baja se explica por ser una universidad «a distancia». Las universidades privadas se distribuyen en todo el recorrido del ranking, pero ocupando las dos posiciones primeras. El caso de la universidad de Navarra es excepcional.

Este ranking de las universidades españolas es el primer intento serio de producir una clasificación con datos oficiales fiables. Es útil para las familias como ayuda para tomar decisiones. Puede resultar imprescindible para las universidades si quieren planificar sus recursos y funcionamiento de forma comparada con las otras universidades. Sugiere además una serie de ideas e hipótesis que sería necesario investigar en los próximos años en las áreas de Sociología de la Educación, Sociología de las Organizaciones, y Sociología de la Ciencia. Los estudiantes uni- 


\section{Gráfico 9}

Calidad de las universidades según su antigüedad

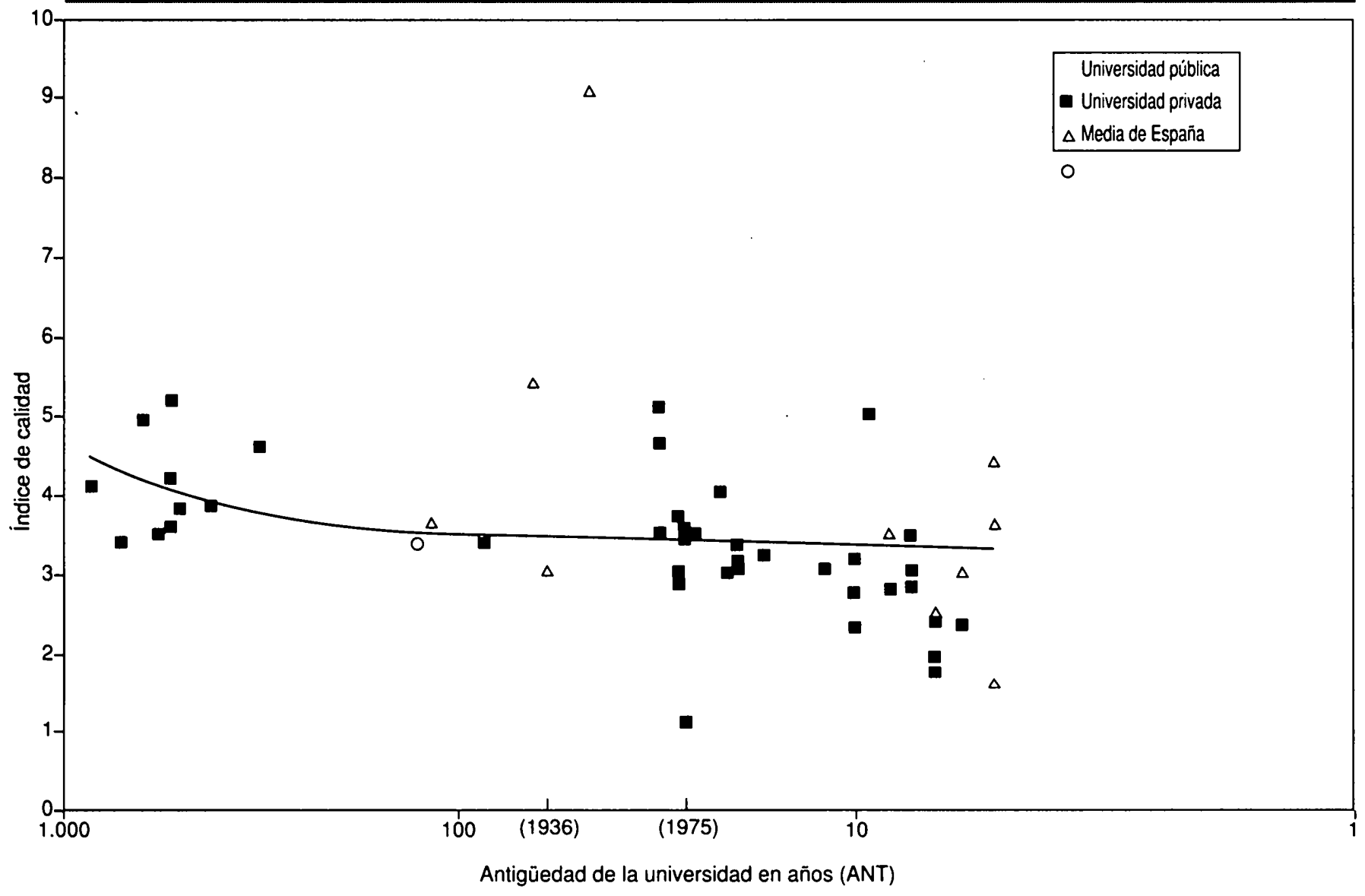

Nota: ANT cs la antigüedad de la universidad en años, y el İ́dice de calidad de las universidad es el İ́ndice técnico conforme a la fórmula (FET * $2+\mathrm{PRO} * 10+\mathrm{LBE}+\mathrm{MPR}+\mathrm{TDE} * 10+\mathrm{ETC}$ ) $/ 60$. Ambos correlacionan 0,25 . Si sólo se tienen en cuenta las universidades públicas la correlación es mayor, de 0,44 . La linea es la regresión lineal. Se calculan los cuadrados menores respecto a una linea representada por la ccuación: $Y=m X+b$, donde $m$ es la pendiente y b el intercepto. La variable ANT uriliza una escala logaritmica.

versitarios que están ahora en las aulas serán los que avanzarán en la discusión de los datos e hipótesis aquí ofrecidas.

\section{Componentes de la calidad}

Conviene investigar qué es «calidad», y cómo se relaciona con los indicadores y universidades aquí analizadas. La antigüedad es un mérito añadido a las universidades. Las universidades antiguas tienden a ser mejores, aunque no les garantiza la excelencia. Hay universidades muy antiguas, como Valladolid, que ocupa el puesto $23^{\circ}$ del ranking. El Gráfico 9 compara calidad con antigüedad. La correlación es positiva, pero 0,44 si se tienen en cuenta las universidades públicas. La calidad se mide mediante el indice técnico, que incluye a todas las universidades públicas y privadas, y oscila entre 1,5 y 8,6 . Funciona aproximadamente como una nota tradicional (de cero a diez). La antigüedad se mide en años en una escala logarítmica. Hay una cierta tendencia a aumentar la calidad en las universidades más antiguas (sobre todo las medievales), y disminuir cuando las universidades son muy nuevas. Lo que interesa es la distancia a la recta de regresión que es la norma estándar. En el gráfico la «recta de regresión» aparece como una curva, pues la antigüedad se presenta en escala logarítmica para poder incluir todos los casos en el mismo gráfico.

Entre las universidades más antiguas, Complutense, La Laguna, y Barcelona tienen una calidad superior a lo esperable según su antigüedad. En el caso de Complutense no es sólo la antigüedad lo que cuenta, sino su centralidad y concentración de recursos capitalinos. En cambio, entre las universidades medievales de calidad más regular está Valladolid. Curiosamente, las universidades privadas se ajustan bastante bien a la pauta estándar, unas por encima (Deusto, Nebrija, Europea de Madrid) y otras por debajo (Pontificia de Salamanca, UOC). 
Pero lo más llamativo es la excelente posición de Pontificia de Comillas y, sobre todo, Navarra. Está claro que en estas dos universidades no prima tanto la antigüedad (fueron creadas en torno a la Guerra Civil), sino su estatuto especial, y los recursos que tienen. Entre las públicas destacan las dos autónomas (Autónoma de Barcelona por encima de Madrid), y sobre todo Pompeu Fabra entre las más modernas. Con mala calidad, a pesar de su antigüedad, está la UNED. En las universidades muy nuevas la calidad disminuye mucho. Unos años después aumentan un poco de calidad. La excelencia de una universidad de menos de diez años tiene que ser limitada. Se observa que el franquismo (las fechas de 1936 y 1975 están marcadas en el gráfico) produce universidades de calidad muy variada, a pesar de su insistencia en que todas las universidades españolas eran de la misma calidad. Los datos demuestran que eso es falso. En cambio, las universidades más modernas parecen, como las medievales, más homogéneas.

Ya se ha demostrado que un indicador esencial en la calidad universitaria es la tasa de profesorado. El Gráfico 10 pone en relación la tasa de profesorado medida en número de profesores por cada cien estudiantes, con la calidad global según el indice técnico, alcanzando una correlación muy alta $(0,72)$. Es uno de los gráficos en que el sistema universitario español

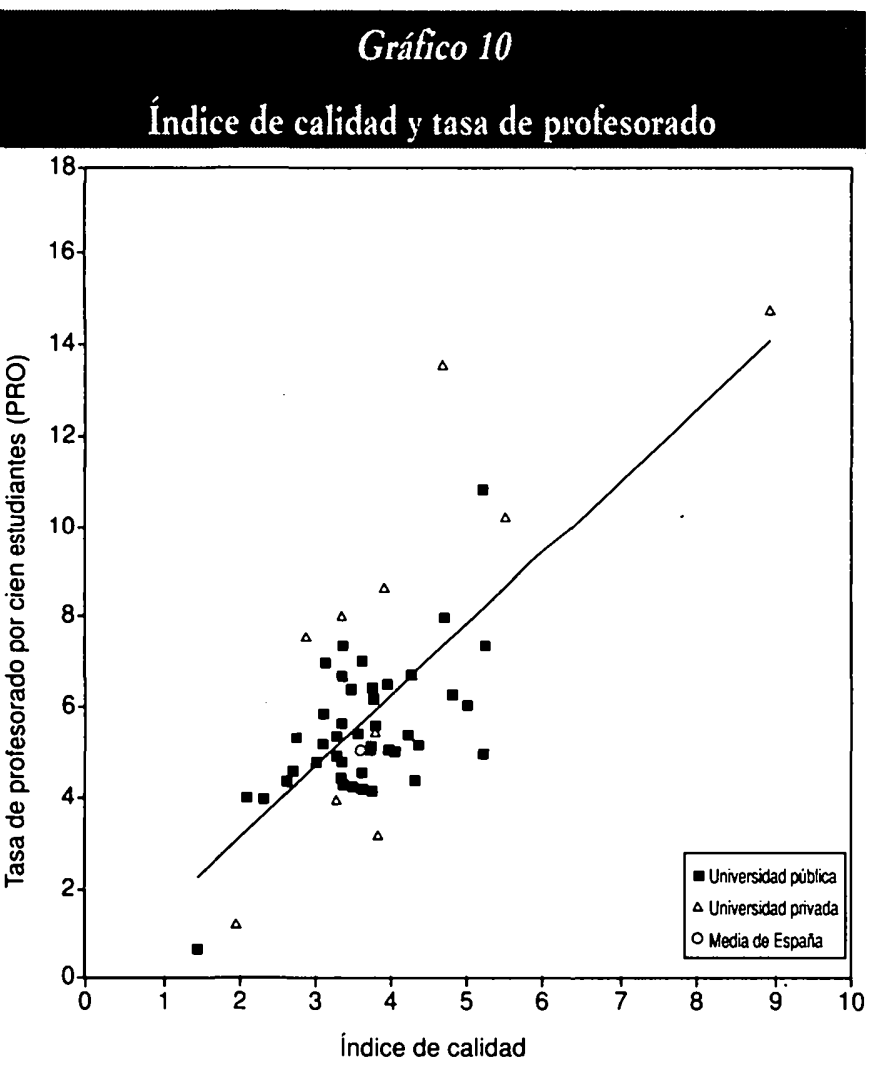

Nota: El Índice de calidad de las universidades es el Índice técnico conforme a la fórmula (FET * 2+ PRO * $10+\mathrm{LBE}+\mathrm{MPR}+\mathrm{TDE} * 10+\mathrm{ETC}) / 60$. Ambos correlacionan 0,72. La linea muestra la regresión lineal. Se calculan los cuadrados menores respecto a una linea representada por la ecuación: $Y=m X+b$, donde $m$ es la pendiente $y$ b el intercepto. se ve más claro. Hay un núcleo central de universidades muy homogéneas, casi todas públicas. En la periferia de este núcleo están la mayoría de las universidades privadas. En posición muy atrasada hay dos universidades, una privada y otra pública, que son las dos «a distancia» (UNED y UOC). Adelante del todo hay una punta de lanza que representa la universidad de más calidad de España: la privada de Navarra. Destaca con mucho respecto del resto. Separadas del núcleo, y tendiendo hacia arriba (es decir, con más profesorado que la calidad que logran) están tres universidades: Antonio de Nebrija (con mucho profesorado, siendo una universidad fundamentalmente tecnológica), Pompeu Fabra que es la pública que más destaca, y Pontificia de Comillas que es la número dos del ranking.

En la periferia del núcleo están las privadas; algunas con una buena dotación de profesorado, como San Pablo, Alfonso X y, sobre todo, Europea de Madrid. En cambio, hay también universidades privadas con poco profesorado, como Pontificia de Salamanca y, Deusto. La posición de Deusto es llamativa, pues tiene muy poco profesorado, y además el nivel de calidad que obtiene (medido por el índice técnico) no es el que se le suele conceder popularmente. Es una universidad con bastante prestigio, y que, sin embargo, en los indicadores no presenta niveles altos. Hay algo confuso en el caso de Deusto que convendría investigar. El panorama del sistema universitario espanol está muy claro en este gráfico. Los indicadores de calidad utilizados no se aplican exactamente igual a las universidades a distancia, por lo que su situación retrasada debe explicarse en parte por su estructura de docencia no presencial. Además de esta retaguardia, el resto del núcleo, periferia del núcleo, avanzadilla, y vanguardia describen muy bien los diversos niveles de excelencia de las universidades españolas.

Un factor de modernidad y diversidad empleado es la feminización de las universidades. Ya se ha señalado que apenas correlaciona con otros factores de calidad, pero que es necesario incluirlo en el análisis. Gráfico 11 relaciona concretamente la feminización del profesorado con la calidad, mostrando una ausencia llamativa de correlación $(0,07)$. Éste es un ejemplo de un núcleo difuso, en que una calidad media de universidades da origen a tasas muy diferentes de feminización del profesorado, que van desde $20 \%$ a $45 \%$. Navarra, con un indice técnico de calidad muy alto, se ajusta a la norma, apareciendo sobre la recta de regresión. Los triángulos de abajo son las tres universidades politécnicas, que tienen muy pocas profesoras (y estudiantas). Otras universidades cercanas, es decir, en la parte baja del gráfico, son Cantabria, Jaén, o Pontificia de Comillas, que destacan por tener estudios técnicos. En cambio, arriba hay universidades de profesoras, fundamentalmente UNED y Europea de Madrid. Ambas destacan por ser universidades de profesoras y con estudiantes-varones. No hay, pues, una correlación entre ambas variables ( 0,07 es muy bajo), pero sí es posible ver tendencias en las universidades y localizar 


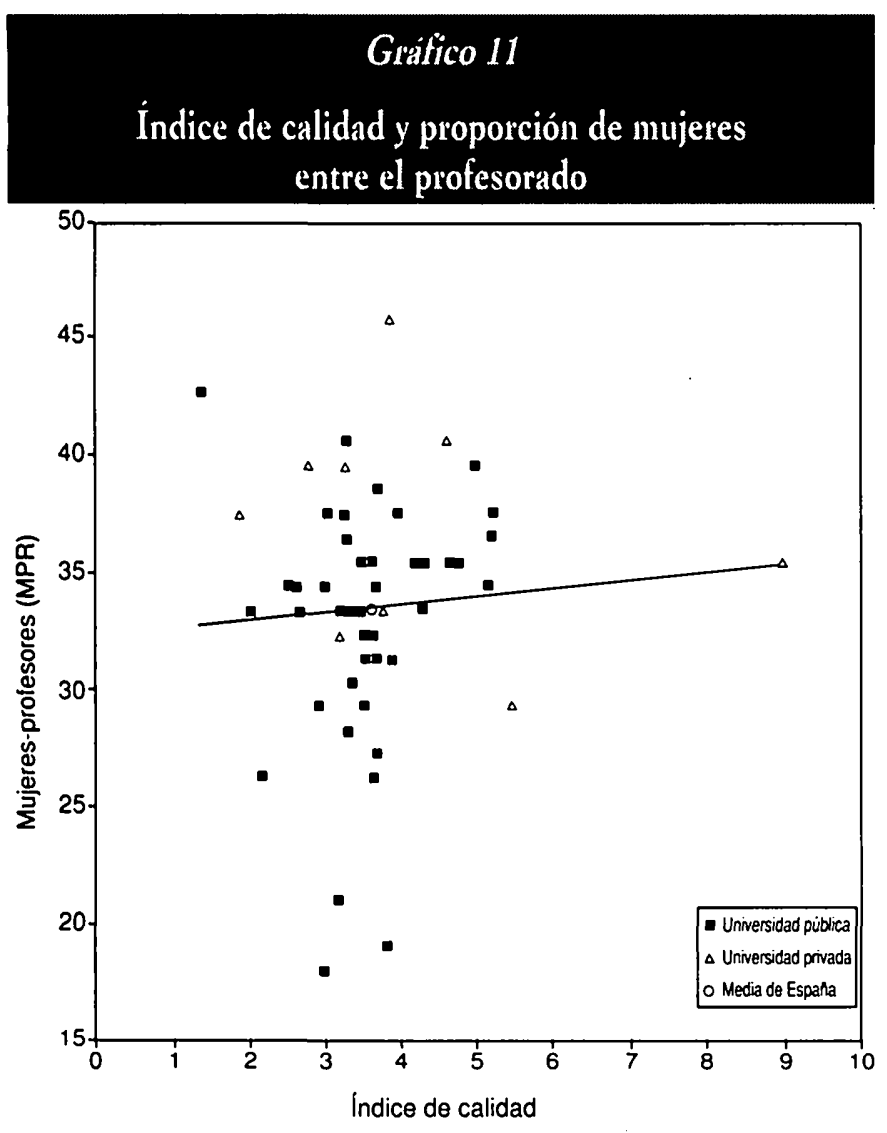

Nota: El Índice de calidad de las universidades es el Índice técnico conforme a la fórmula $(\mathrm{FET} * 2+\mathrm{PRO} * 10+\mathrm{LBE}+\mathrm{MPR}+\mathrm{TDE} * 10+\mathrm{ETC}) / 60$. MPR es el porcentaje de mujeres entre cl profesomdo. Ambos correlacionan 0,07. La línea muestra la regresión lineal. Se calculan los cuadmados menores respecio a una linea representada por la ecuación: $Y=m X+b$, donde $m$ es la pendiente ybcl intercepto.

tipos diversos. La calidad no depende, pues, de variables postmodernas (como feminización del profesorado), sino más bien de variables estructurales como recursos o productividad.

El Gráfico 12 presenta la relación entre bibliotecas y calidad. Las bibliotecas se miden aquí en números de libros por estudiante, y la calidad por el índice técnico. La relación es bastante alta $(0,66)$. Hay un núcleo central, con una cierta dispersión hacia arriba: una tendencia a incrementar las bibliotecas por encima de la calidad final que luego obtienen. El grupo de retaguardia es más numeroso, con una universidad que destaca atrás del todo que es UNED. En ese grupo de retaguardia se juntan las «a distancia» con las politécnicas, algunas públicas muy recientes, como Burgos y Almería, y las peores privadas, como San Pablo y Alfonso X. Es decir, el cruce de calidad y bibliotecas, que mantiene una correlación positiva y alta, discrimina bien el conjunto de universidades que tienen una calidad baja. Algunas buenas universidades, pero grandes, están mejor de calidad que de número de volúmenes de biblioteca por estudiante: Complutense, Autónoma de Barcelona, y Barcelona. Esto es lógico, pues tienen buenas bibliotecas, pero un número excesivo de estudiantes. En cambio, otras universidades

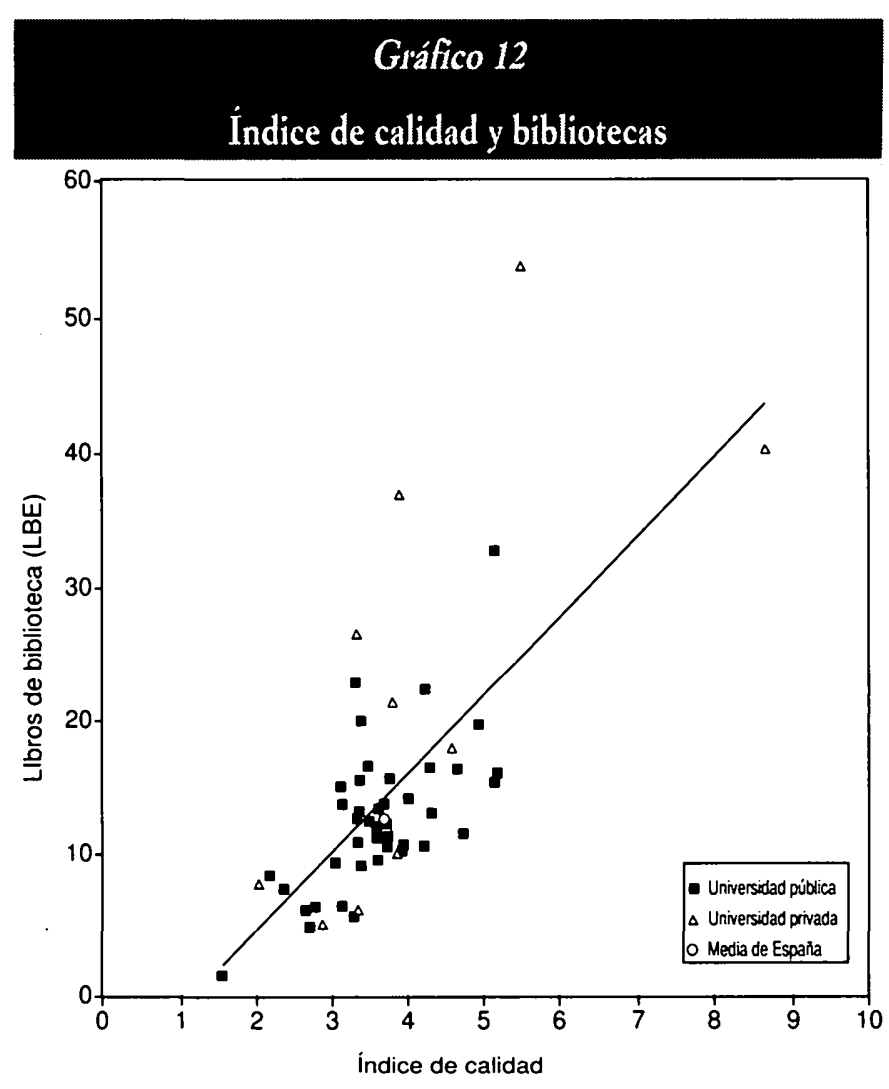

Nota: El Índice de calidad de las universidades es el Índice técrico conforme a la fórmula (FET * $2+\mathrm{PRO} * 10+\mathrm{LBE}+\mathrm{MPR}+\mathrm{TDE} * 10+\mathrm{ETC}) / 60$. LBE es el número de libros de la biblioteca por estudiante. Ambos correlacionan 0,66 . La linea muestra la regresión lineal. Se calculan los cuadrados menores respecto a una linea representada por la ecuación: $Y=m X+b$, donde $m$ es la pendiente y bel intercepto.

más reducidas, que han conseguido frenar su crecimiento (del número de estudiantes), se escapan del núcleo hacia arriba: Pontificia de Comillas sobre todo, luego Deusto, Pompeu Fabra, Pontificia de Salamanca e incluso algo Baleares y Salamanca. Navarra tiene una calidad excelente, pero una biblioteca de 596.000 volúmenes, impropia para una universidad de su rango. Relativa al número de estudiantes, Pontificia de Comillas con una biblioteca de 456.000 ejemplares está bastante mejor situada, arriba del todo. Afortunadamente, la tendencia parece ser la de invertir más en bibliotecas, aunque el núcleo central es bastante homogéneo y con una dotación de bibliotecas deficiente.

Pero la calidad no debe medirse solamente en relación a los recursos, sino sobre todo a la productividad. Quizás el mejor indicador de todos es la producción de doctores. El Gráfico 13 muestra que la relación entre calidad y producción de títulos de doctor es altísima, quizás una de las más importantes $(0,80)$. La relación es muy lineal, es decir, apenas existe un núcleo redondo, sino una tendencia claramente en fila. Hacia arriba hay una cierta divergencịa a la izquierda, que señala que a niveles altos de calidad las universidades se convierten realmente en universidades-investigadoras. La relación es tan estrecha que 


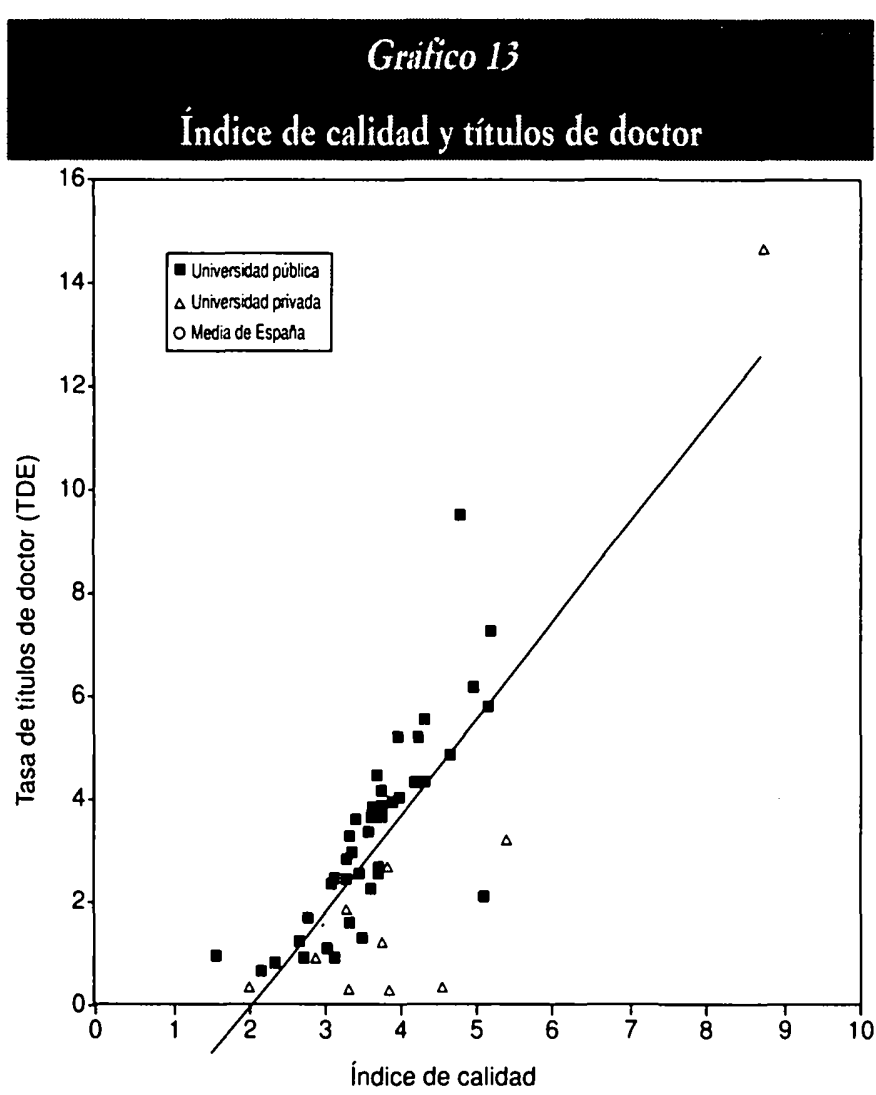

Nota: El Índice de calidad de las universidades es el Índice técnico conforme a la fórmula $\left(\mathrm{FET} * 2+\mathrm{PRO} * 10+\mathrm{LBE}+\mathrm{MPR}+\mathrm{TDE}^{*} 10+\mathrm{ETC}\right) / 60$. TDE se refiere a los titulos de doctor por mil estudiantes. Ambos correlacionan 0,80. La linea muestra la regresión lineal. Se calculan los cuadrados menores respecto a una linea representada por la ecuación: $Y=m X+b$, donde $m$ es la pendiente $y$ b el intercepto.

permite discriminar bien cuáles son las mejores universidades-investigadoras en España: Navarra, las dos autónomas, Universidad de Barcelona y Complutense. Curiosamente, Pontificia de Comillas (privada) y Pompeu Fabra (pública) son excelentes colleges, pero no han desarrollado suficientemente el tercer ciclo. Pompeu Fabra es posible que lo haga, pues es una universidad muy joven. No tanto así Pontificia de Comillas. Algunas privadas, en la parte más baja del gráfico, ni siquiera se han planteado seriamente producir doctores. Deusto, en mitad del bloque de universidades públicas, aparece en unos niveles bajos. Los más bajos son los de las universidades a distancia, que se especializan fundamentalmente en títulos intermedios, no en doctorado, y con un nivel de productividad muy bajo. Navarra aparece en una posición separada del resto de universidades españolas, tanto por su alta calidad como, sobre todo, por su producción mayor de lo esperable de títulos de doctor. Si Navarra y las dos autónomas marcan la pauta de desarrollo de las universidad españolas, el futuro puede ser optimista; algo que se insinúa en la tendencia del presente gráfico.

La calidad de la universidad debe estar en estrecha relación con la productividad, medida por la proporción de estudiantes que realmente terminan la carrera en los cursos previstos. Se
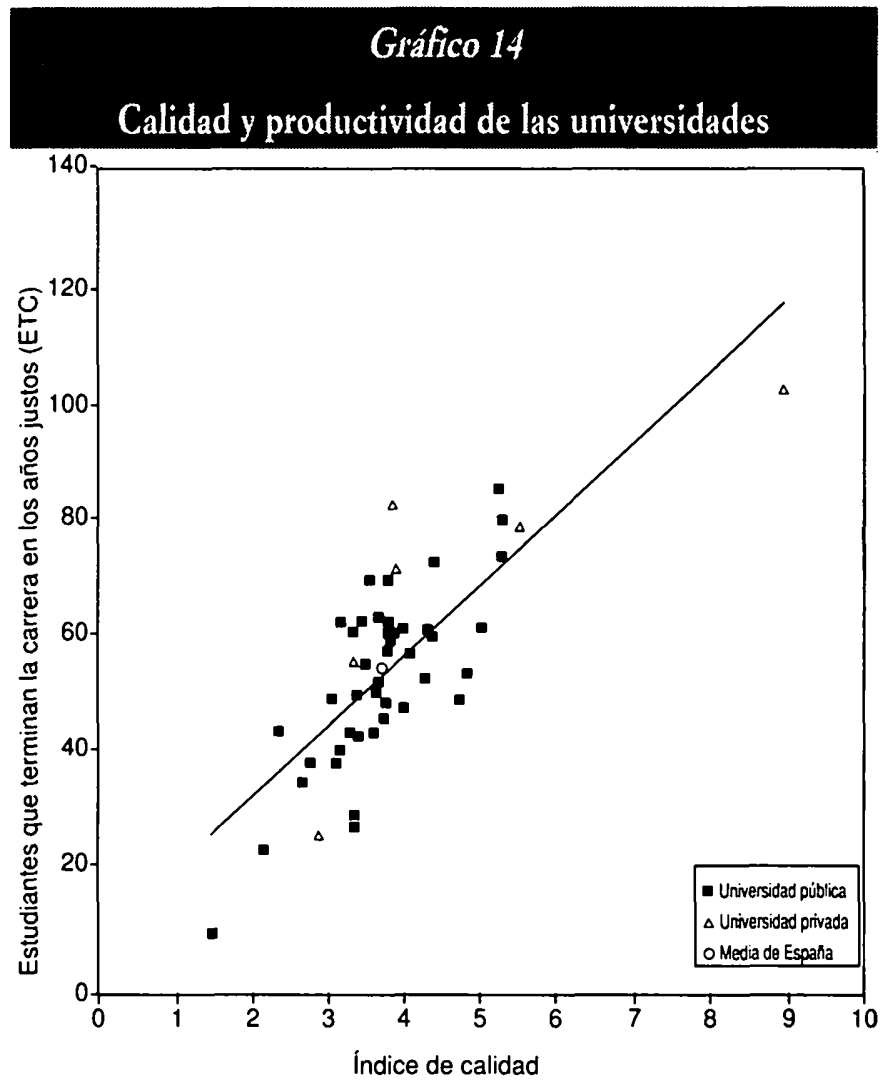

Nota: El Índice de calidad de las universidades es el Índice técnico conforme a la fórmula $($ FET * $2+\mathrm{PRO} * 10+\mathrm{LBE}+\mathrm{MPR}+\mathrm{TDE} * 10+\mathrm{ETC}) / 60$. ETC es el porcentaje de estudiantes que terminan la carrera en los años justos. Ambos indicadores correlacionan 0,77 . La línea muestra la regresión lineal. Se calculan los cuadrados menores respecto a una línea representada por la ecuación $\mathrm{Y}=\mathrm{mX}+\mathrm{b}$, donde $\mathrm{m}$ es la pendiente y b el intercepto.

podría haber medido según el número de cursos previstos más uno, aumentado así la proporción. Pero en el gráfico no importa la proporción exacta, como la relación entre productividad y calidad. El Gráfico 14 muestra esa relación, cuya correlación es 0,77 . La relación es bastante lineal, y con tendencia a subir, aunque es frenada por la situación de Navarra en la vanguardia, que ya no puede aumentar más. De nuevo se observa un núcleo, en este caso alargado, aumentando así la correlación. Hay una retaguardia dispersa, y una vanguardia reducida que termina en el caso atípico, pero ejemplar, de Navarra. En la retaguardia están UNED, Huelva, San Pablo (privada), y Las Palmas, todas ellas universidades de calidad escasa y productividad también muy baja. Tras Navarra, la vanguardia está formada por la universidad privada Antonio de Nebrija, y luego tres universidades en línea, que son de las mejores que hay en España: Pompeu Fabra, Complutense, y Autónoma de Barcelona. La Universidad de Barcelona sigue a continuación, con alta calidad, pero con una productividad mucho más baja de lo que le corresponde. Este gráfico cristaliza ya las relaciones entre calidad y tipos de universidades en España.

Podría decirse que la calidad empieza con la antigüedad de una universidad. Las universidades antiguas han crecido más 
$y$ han acumulado recursos de equipamiento y biblioteca. Han diversificado mucho los saberes y carreras, concentrándose en carreras largas. Han conseguido bastante profesorado, y bueno. Pero las universidades públicas no han sabido controlar el crecimiento, y en tasas el profesorado es más bajo de lo que debiera. La antigüedad explica también la creación y desarrollo del doctorado, y curiosamente la feminización de su profesorado. Pero la calidad se explica sobre todo por recursos, en gran parte por el profesorado, así que la antigüedad no lo es todo, incluso a veces es un obstáculo. La relación entre profesorado y calidad es muy alta, mientras que no lo es (en absoluto) que ese profesorado sea femenino. Una variable importantísima es la dotación de recursos de biblioteca. Aquí las diferencias son importantes, pues la situación española es muy deficiente. La media de biblioteca es 0,4 millones de volúmenes, cuando el mínimo para ser universidad-investigadora a nivel internacional es 2,0 millones. Las (diez) mejores universidades-investigadoras de Estados Unidos y Canadá tienen todas más de 7,0 millones de volúmenes. La dotación de bibliotecas explica la variación entre universidades, pero no puede como indicador (debido a la escasez de libros) explicar la calidad global de la universidad. La calidad está más relacionada con la producción de títulos de doctor. La relación entre calidad y doctorado es 0,80 . Con el análisis se entiende que la relación más estratégica es entre calidad y productividad de las carreras.

Aunque los gráficos anteriores van variando y muestran dispersiones diferentes de universidades, se observa que existen grupos diferentes de universidades, así como posiciones claras de universidades concretas. Hay generalmente un núcleo de universidades públicas más o menos alargado. En la periferia de ese núcleo se suelen situar las universidades privadas. Hay una vanguardia muy destacada, con una posición siempre muy adelantada de la universidad privada de Navarra. Suele verse una vanguardia mixta de universidades privadas (generalmente, Pontificia de Comillas) y públicas (las dos autónomas, Pompeu Fabra, Complutense, y a veces Barcelona) que destacan por su excelencia, y que parecen marcar la pauta de desarrollo del resto de universidades. La cola o retaguardia está compuesta de universidades a distancia, algunas privadas de mala calidad, y algunas públicas provinciales, recientes, y con pocos recursos. Todo sugiere que la realidad es más tozuda que los deseos de la población o los discursos de los políticos o políticas.

\section{Dinámica de la selectividad}

Una realidad es la calidad objetiva de las universidades espanolas. Otra distinta es la calidad que la población atribuye a cada universidad. La nota media de selectividad de los 350.000 estudiantes que eligen universidad muestra las elecciones de esas familias, tanto de universidad, como de carrera. La relación entre selectividad (a menudo subjetiva) y calidad (objetiva, medida por los indicadores de recursos y productividad) es la clave para entender las disonancias sociales que se observan en el sistema universitario español. La Tabla 7 presenta las notas medias de selectividad de cada universidad para el curso 1999-2000. A pesar de lo tedioso y complicado que es calcular estos datos, se presentan dos indicadores diferentes: la nota media de todas las carreras de cada universidades en ese año concreto, y la media de los/as estudiantes de todas las carreras de cada universidad. El primer indicador no tiene en cuenta el tamaño de las carreras. El segundo es más complicado pero mide realmente la nota de un/a estudiante medio de esa universidad. Las diferencias son pequeñas: la nota media de carreras es 5,69 (isobre diez!), y la media de estudiantes es 5,65. La exclamación sobre la escala de cero a diez es que las medias de los estudiantes españoles son lamentablemente bajas. Los estudiantes apenas aprueban. La información oficial sólo se ha podido obtener de 42 y 44 universidades, todas ellas públicas. Se especifica cuántas carreras de cada universidad han dado información, la nota media (por carreras o por estudiante), y también el ranking de todas las universidades.

La correlación de las notas de selectividad por carreras y por estudiante es 0,94 . La correlación de los dos ranking (por notas medias de carreras y de estudiantes) correlaciona 0,89 . El número de carreras con información en ambos indicadores correlaciona 0,90. Estamos, pues, ante unos datos que muestran una alta consistencia interna. La sorpresa es que la universidad con notas más altas de selectividad (por carrera y por estudiante) es Las Palmas, que en el ranking de calidad real es una universidad más bien regular: ocupa el puesto $300^{\circ}$ de 44 . El que sea la más elegida, y por estudiantes con una nota más elevada de selectividad, tiene que ver con que es la única universidad en la isla (frente a La Laguna en la otra isla, Tenerife), que es una universidad fundamentalmente politécnica, y muy reciente. No puede, pues, considerarse que la media de notas de selectividad de cada cohorte que ingresa en la universidad es un indicador exacto de la calidad de las universidades. Por eso ni siquiera se ha incluido en la fórmula de los índices de calidad. Sin embargo, su distribución es importante de analizar. Las universidades politécnicas, y las que no tienen el título de «politécnicas», pero se especializan en carreras tecnológicas, obtienen las medias más elevadas. Así, por ejemplo, las tres politécnicas, Las Palmas, y Cantabria. Pero también están universidades que atraen a estudiantes como Pompeu Fabra y Autónoma de Barcelona en Cataluña, La Laguna en Canarias, La Coruña en Galicia, Salamanca y Valladolid en Castilla. El poder de atracción está relacionado con la calidad, pero de forma no exacta.

La relación gráfica entre calidad y selectividad aparece en el Gráfico 15. La relación es positiva (si fuera negativa la diso- 


\begin{tabular}{|c|c|c|c|c|c|c|c|}
\hline \multicolumn{2}{|c|}{$\begin{array}{l}\text { Media de notas de selectividaid para ingresar en las universidades públicas en el curso } 1999-2000 \\
\text { Media de notas por carrera }\end{array}$} & \multicolumn{3}{|c|}{ Media de notas por carrera } & \multicolumn{3}{|c|}{ Media de notas por estudiante/a de cada carrera } \\
\hline & & $\begin{array}{c}\text { Carreras } \\
\text { con información }\end{array}$ & $\begin{array}{c}\text { Media } \\
\text { de PAAU de todas } \\
\text { las carreras }\end{array}$ & Ranking & $\begin{array}{l}\text { Carreras con } \\
\text { información }\end{array}$ & $\begin{array}{c}\text { Media de } \\
\text { PAAU de } \\
\text { los/as estudiantes }\end{array}$ & Ranking \\
\hline UAH & Alcalá de Henares & 30 & 5,76 & 17 & 30 & 5,83 & 11 \\
\hline UAL & Alicante & 41 & 5,57 & 28 & 37 & 5,56 & 25 \\
\hline UALM & Almeria & 24 & 5,14 & 42 & 19 & 5,11 & 41 \\
\hline UAB & Autónoma Barcelona & 56 & 5,93 & 12 & 56 & 5,95 & 7 \\
\hline UAM & Autónoma Madrid & 37 & 5,73 & 19 & 37 & 5,68 & 21 \\
\hline UBA & Barcelona & 56 & 5,80 & 16 & 56 & 5,82 & 13 \\
\hline UB & Burgos & 19 & 5,29 & 38 & 17 & 5,22 & 39 \\
\hline UCA & Cádiz & 57 & 5,35 & 37 & 57 & 5,26 & 38 \\
\hline UCN & Cantabria & 26 & 6,25 & 3 & 20 & 6,42 & 3 \\
\hline UCAR & Carlos III & 15 & 5,87 & 14 & 15 & 5,81 & 14 \\
\hline UCLM & Castilla-La Mancha & 75 & 5,96 & 8 & 75 & 5,62 & 23 \\
\hline UCM & Complutense & 58 & 5,92 & 13 & 58 & 5,81 & 14 \\
\hline UCO & Cordoba & 38 & 5,48 & 33 & 38 & 5,32 & 36 \\
\hline ULC & La Coruña & 36 & 5,98 & 6 & 34 & 5,86 & 10 \\
\hline UEX & Extremadura & 69 & 5,94 & 10 & 69 & 5,81 & 14 \\
\hline UGI & Girona & 35 & 5,39 & 36 & 35 & 5,52 & 27 \\
\hline UGR & Granada & 75 & 5,48 & 33 & 48 & 5,46 & 32 \\
\hline UHU & Huelva & 20 & 5,15 & 41 & 20 & 5,12 & 40 \\
\hline UIB & Islas Baleares & 37 & 5,11 & 43 & 37 & 5,08 & 43 \\
\hline UJA & Jaén & 35 & 5,16 & 40 & 31 & 5,11 & 41 \\
\hline UJCS & Jaume I & 18 & 5,45 & 35 & 18 & 5,31 & 37 \\
\hline ULL & La Laguna & 39 & 5,83 & 15 & 28 & 5,91 & 9 \\
\hline URI & La Rioja & 20 & 5,29 & 38 & 14 & 5,34 & 35 \\
\hline ULE & León & 33 & 5,50 & 32 & 33 & 5,36 & 34 \\
\hline UdL & Leida & 32 & 5,54 & 30 & 32 & 5,47 & 31 \\
\hline UMA & Málaga & 55 & 5,57 & 28 & 54 & 5,44 & 33 \\
\hline UMU & Murcia & 45 & 5,94 & 10 & 44 & 5,72 & 19 \\
\hline UOV & Oviedo & 54 & 5,75 & 18 & 36 & 5,73 & 18 \\
\hline UPV & Pais Vasco & 79 & 5,68 & 21 & 70 & 5,68 & 21 \\
\hline UPGC & Las Palmas & 43 & 6,95 & 1 & 40 & 7,07 & 1 \\
\hline UPC & Politécnica Cataluña & 51 & 5,98 & 6 & 51 & 6,08 & 4 \\
\hline UPM & Politécnica Madrid & 23 & 6,42 & 2 & 23 & 6,43 & 2 \\
\hline UPVA & Politécnica Valencia & 44 & 6,00 & 5 & 44 & 5,98 & 6 \\
\hline UPF & Pompeu Fabra & 16 & 6,15 & 4 & 16 & 6,02 & 5 \\
\hline UPNA & Pública Navarra & 20 & 5,62 & 26 & 19 & 5,57 & 24 \\
\hline URV & Rovira i Virgili & 33 & 5,61 & 27 & 33 & 5,51 & 29 \\
\hline USA & Salamanca & 68 & 5,52 & 31 & 33 & 5,93 & 8 \\
\hline UST & Santiago & 51 & 5,66 & 23 & 39 & 5,76 & 17 \\
\hline USE & Sevilla & 61 & 5,70 & 20 & 61 & 5,52 & 27 \\
\hline UNED & UNED & 16 & 5,00 & 44 & 16 & 5,00 & 44 \\
\hline UVEG & Valencia & 50 & 5,96 & 8 & 50 & 5,71 & 20 \\
\hline UVA & Valladolid & 75 & 5,63 & 25 & 48 & 5,83 & 11 \\
\hline UVI & Vigo & 42 & 5,67 & 22 & 42 & 5,51 & 29 \\
\hline UZA & Zaragoza & 60 & 5,65 & 24 & 57 & 5,54 & 26 \\
\hline Media d & las universidades: & 42 & 5,69 & 44 & 38 & 5,65 & 44 \\
\hline
\end{tabular}

Fuente: Ministerio de Educación y Ciencia. «Notas de corte 1998 -1999 por enseñanza», en bttp:wurv.mec.es

Nota: Media de notas por carrera es la media de las notas de PAAU que se exigen en una universidad para entrar en cada carrera universitaria. La media de notas por estudiante/a de cada carrera es la media de las notas de PAAU de los as estudiantes que se incorporan a las carneras en el curso 1999.2000 en cada universidad. La información se obtiene directamente del Ministerio de Educación y Ciencia. El número de carreras con información difiere a veces de los dos casos dependiendo de que número de plazas que se ofrecen en una carrera sea un SL (sin límite); entonces la nota de acceso no se tiene en cuenta por la imposibilidad de ponderar la cifra de estudiantes. 


\section{Gráfico 15}

Relación entre notas de selectividad e Índice de calidad de las universidades

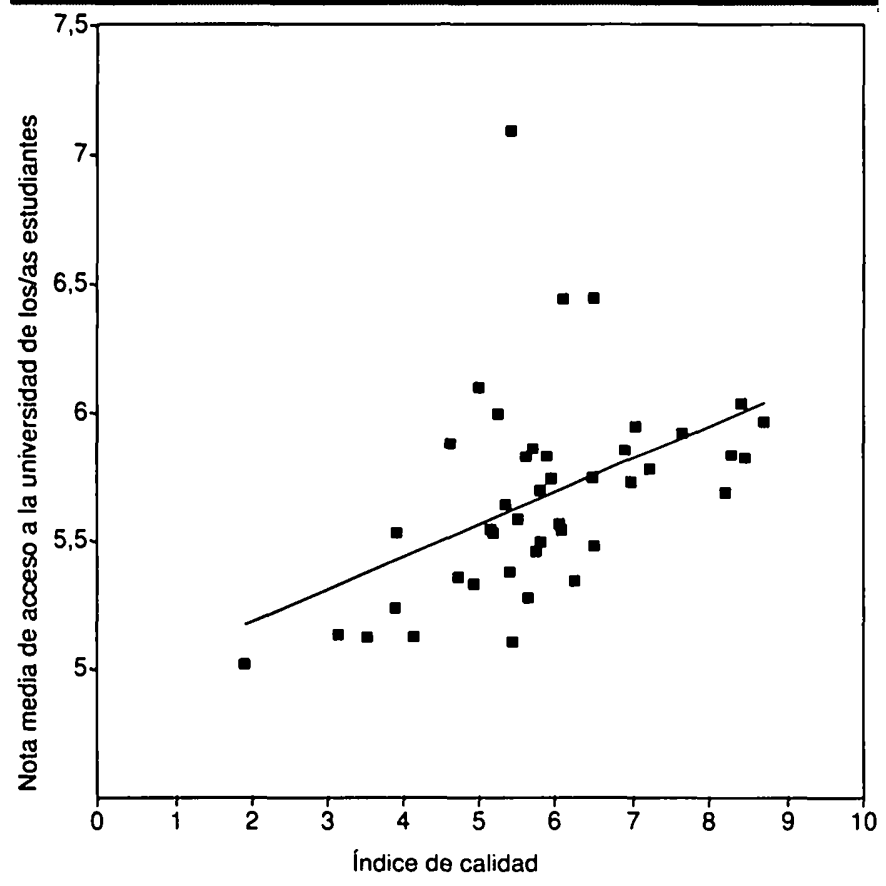

Nota: El Índice de calidad de las universidades es el Índice técnico conforme a la fórmula $($ FET $* 2+\mathrm{PRO} * 10+\mathrm{LBE} * 2+\mathrm{MPR} / 2+\mathrm{TDE} * 15+\mathrm{ETC}) / 40$, que se relaciona con la media de las notas mínimas de acceso a cada carrera de los/as estudiantes que acceden a la universidad en 1999. Ambos correlacionan 0,46. La linea muestra la regresión lineal. Se calculan los cuadrados menores respecto a una linca representada por la ecuación: $Y=m X+b$, donde $m$ es la pendiente y b el intercepto.

nancia social sería extrema) pero no es excesivamente alta: 0,46. Eso significa que a veces las familias o jóvenes se equivocan al elegir la mejor universidad posible. Quizás al no tener información eligen la segunda opción que más les favorece, sin tratar de averiguar cuál es la primera mejor. Aquí se utiliza el indice investigador de calidad de las universidades, pues es el más elaborado, ya que sólo hay información de selectividad para las universidades públicas. Es una distribución difusa con un cierto, pero irregular, núcleo central. La típica retaguardia es UNED, y en la mitad una serie de universidades muy elegidas en selectividad. Este núcleo de universidades medias de calidad, pero que concentran estudiantes con notas altas de selectividad son claramente las universidades politécnicas. Arriba del todo Las Palmas, seguida de una pareja que son Cantabria y Politécnica de Madrid. Más abajo una macla de tres universidades: Politécnica de Cataluña, Politécnica de Valencia, y Extremadura. En la vanguardia de la distribución hay dos universidades que se ajustan a la norma: Pompeu Fabra y Autónoma de Barcelona. Son realmente dos de las mejores universidades públicas de España (tercera y primera, respectivamente). Van seguidas de tres universidades más: Barcelona (la cuarta del país), Complutense (la segunda), y un poco más abajo Autónoma de
Madrid (la quinta). Se ve claramente que la selección de los/as jóvenes no está equivocada por lo que respecta a las cinco mejores universidades del país. Las cinco coinciden en calidad y notas altas de selectividad.

En el otro extremo la selectividad es también evidente. Las universidades con notas medias más bajas son UNED, Huelva, Jaén, Almería, y Baleares. UNED por ley tiene una nota de selectividad «oficial» de 5,00. Las otras son universidades provinciales, muy nuevas, en que los estudiantes ya tenían tradición de ir a otra universidad a estudiar: a Granada con nota media de 5,46 o a Sevilla con nota media de 5,52 en el caso andaluz; a Madrid o Barcelona en el caso de Islas Baleares (nota media de 5,08, la más baja de España aparte de UNED). Como pueden verse, las diferencias numéricas son sutiles, aunque la sig. nificación es considerable. Las diferencias son pequeñas, pero se refiere a medias de miles de estudiantes, lo que es importante. Con excepción de las carreras técnicas que se concentran en universidades politécnicas o semi-politécnicas, los/as estudiantes eligen bastante bien las universidades de calidad, sobre todo en las regiones donde realmente pueden elegir mejor: Cataluña y Madrid. La elección es doble: de carrera y de universidad. En el futuro sería interesante realizar un análisis por carreras, pero eso supondría un artículo como el actual para cada especialidad.

Con el análisis de la selectividad se cierra el círculo de la investigación sobre la calidad. La Tabla 8 muestra un resumen de las correlaciones entre los indicadores fundamentales, las notas medias de selectividad de los/as estudiantes que ingresan en la universidad, y el indice investigador de calidad que es el que se propone como mejor para evaluar la calidad de las universidades públicas. Lo que más evalúan los/as estudiantes en su selección es el profesorado y la existencia de un buen pro. grama de doctorado. Es decir, se está evaluando positivamente lo que se conoce como «universidad investigadora». También se evalúa positivamente que sea una universidad extensa, con bastantes carreras, y las diversas ramas de la ciencia. No importa tanto si la universidad suspende o aprueba. De hecho, las universidades politécnicas son muy demandadas, siendo las que más suspenden. Tampoco parece importar los recursos de biblioteca. Los/as estudiantes españoles no han aprendido a valorar la importancia de una buena biblioteca. En parte, tienen razón, pues todas las bibliotecas de universidad (quizás salvo Complutense y Barcelona) no valen realmente para investigar o alcanzar unos niveles profesionales desarrollados. A las estudiantes $(54 \%)$ y los estudiantes $(46 \%)$ que ingresan, curiosamente, no parece importarles que el profesorado sea un poco más mujeres. La correlación es negativa: $-0,31$. Es decir, que los estudiantes (de ambos géneros) parece como si discriminasen en contra de las universidades con un porcentaje mayor de profesoras-mujeres. Esto es un resultado sorprendente. Los/as estudiantes eligen un poco más ir a estudiar a univer- 


\section{Tabla 8}

Correlaciones de los indicadores fundamentales con las notas de selectividad y el indice de calidad (universidades puiblicas)

\begin{tabular}{|ccc|}
\hline $\begin{array}{c}\text { Indicadores } \\
\text { fundamentales }\end{array}$ & $\begin{array}{c}\text { Nota de } \\
\text { selectividad }\end{array}$ & $\begin{array}{c}\text { Indice } \\
\text { de calidad }\end{array}$ \\
\hline PIB & 0,24 & 0,31 \\
ANT & 0,13 & 0,44 \\
FET * & 0,33 & 0,48 \\
PRO * & 0,43 & 0,58 \\
LBE * & 0,21 & 0,64 \\
MPR * & $-0,31$ & 0,11 \\
TDE * & 0,35 & 0,83 \\
ETC * & 0,28 & 0,71 \\
\hline Notas selectividad & 1,00 & 0,46 \\
Indice de calidad & 0,46 & 1,00 \\
\hline
\end{tabular}

Fuentes: Tablas 1 y 5 .

Nota: En la elaboración de las correlaciones sólo se incluye a las universidades públicas.

sidades en zonas desarrolladas, y que la universidad sea antigua. Pero el factor de antigüedad sólo correlaciona 0,13.

La selectividad y la calidad correlacionan positivamente y bastante alto $(0,46)$. La calidad final de las universidades correlaciona muy alto con todos los indicadores, fundamentalmente con la producción de doctores $(0,83)$, y la productividad de las carreras de primer y segundo ciclo $(0,71)$. La calidad mide bastante bien los recursos, ya sean institucionales o biblioteca $(0,64)$ como recursos humanos (profesorado 0,58). La universalidad de carreras es un aspecto menos importante, pero muestra una correlación también alta $(0,48)$. El factor menos importante para definir la calidad actual de las universidades espanolas (según nuestro modelo) es la feminización del profesorado, cuya relación es positiva, pero solamente 0,11 . Así como los/as estudiantes valoran más el desarrollo de la región que la antigüedad de la universidad, la calidad, sin embargo, depende más de la antigüedad de la universidad (correlación 0,44) que del desarrollo de la región (aunque es también positivo 0,31 ). Selección y calidad no coinciden totalmente, pero se acercan bastante, mostrando que las decisiones de la población, aun con una falta considerable de información, son bastante apropiadas. Las instituciones sociales están siendo permanen. temente evaluadas por la sociedad a través de los medios de comunicación y las relaciones interpersonales. Lo difícil es poner números a esas evaluaciones.

Convendría tener idea de cuáles son los objetivos de las universidades españolas. No es adecuado crear expectativas irrealizables. Por ejemplo, si las universidades españolas quisieran estar a la altura de universidades investigadoras en el mundo deberían de multiplicar, de media, sus bibliotecas por cinco. Si desean estar en el nivel de buenas universidades inter- nacionales deberían de multiplicar las bibliotecas seguramente por 10 ó 12 . Esto es difícil de realizar. Lo lógico es observar cuáles son los estándares de las diez mejores universidades públicas españolas, y aplicar esos estándares al resto de universidades, sobre todo a las más modernas. La Tabla 9 presenta esos indicadores. Están las diez universidades mejores españolas por orden, desde Autónoma de Barcelona a Alcalá de Henares. No por casualidad hay tres universidades de Barcelona y otras tres de Madrid en esa lista de diez mejores.

El conjunto de las diez mejores universidades presenta indicadores relativamente homogéneos por encima de la media de universidades. Curiosamente, la riqueza regional apenas varía: es solamente un $5 \%$ mayor de las diez mejores universidades. La antigüedad sí es un factor: las universidades mejores son 2,6 veces más antiguas. De los seis indicadores básicos de calidad el que presenta más diferencias con la media de todas las universidades es la producción de doctores $(67 \%$ más en las mejores universidades). Las diferencias son también grandes $(50 \%)$ en número de centros con carreras largas. La productividad es $19 \%$ más alta en las mejores universidades (de media). Hay un $12 \%$ más de libros por estudiante, y una proporción similar de mayor tasa de profesorado ( $11 \%$ más). Pero si en vez de la media de universidades se tiene en cuenta la media de toda España, global, entonces las tasas conseguidas por las diez mejores universidades son $28 \%$ más de profesores, y $29 \%$ más de libros. Así que depende un poco de cómo se mida. La variable que se diferencia menos, pero que es positiva, es feminización del profesorado. Las diez mejores universidades tienen de media $6 \%$ más de mujeres-profesoras. La nota media de selectividad de las mejores universidades no es mucho mayor que la del resto de universidades. Solamente $3 \%$ más alta (de 5,65 a 5,84). El ICI, o índice de calidad investigadora, varía $22 \%$, lo que es considerable. Esta tabla sirve, pues, para establecer las metas de las universidades españolas en su conjunto para las próximas décadas. El ideal sería tender hacia los siguientes indicadores: 15 centros con carreras largas (Facultades o Escuelas Técnicas Superiores); entre 7 y 8 profesores por cien estudiantes; al menos 20 libros de biblioteca por estudiante; $40 \%$ de profesoras del total de profesorado universitario; 6 ó 7 títulos de doctor por mil estudiantes; y que $75 \%$ de los/as estudiantes terminen la carrera en los años previstos. Si cualquier universidad española consigue estos indicadores puede ser considerada de excelencia dentro del contexto español. El problema es que tiene que conseguir los seis.

En España en la actualidad hay una polémica considerable sobre la calidad de las universidades (públicas y privadas). No hay todavía acuerdo sobre cómo medir esa calidad, pero sí en que hay que cuantificarla de forma científica y lo antes posible. El presente artículo es parte de un estudio mucho más extenso titulado Excelencia: Calidad de las universidades españolas, terminado en el año 2000 (538 páginas). Los tres mismos autores 


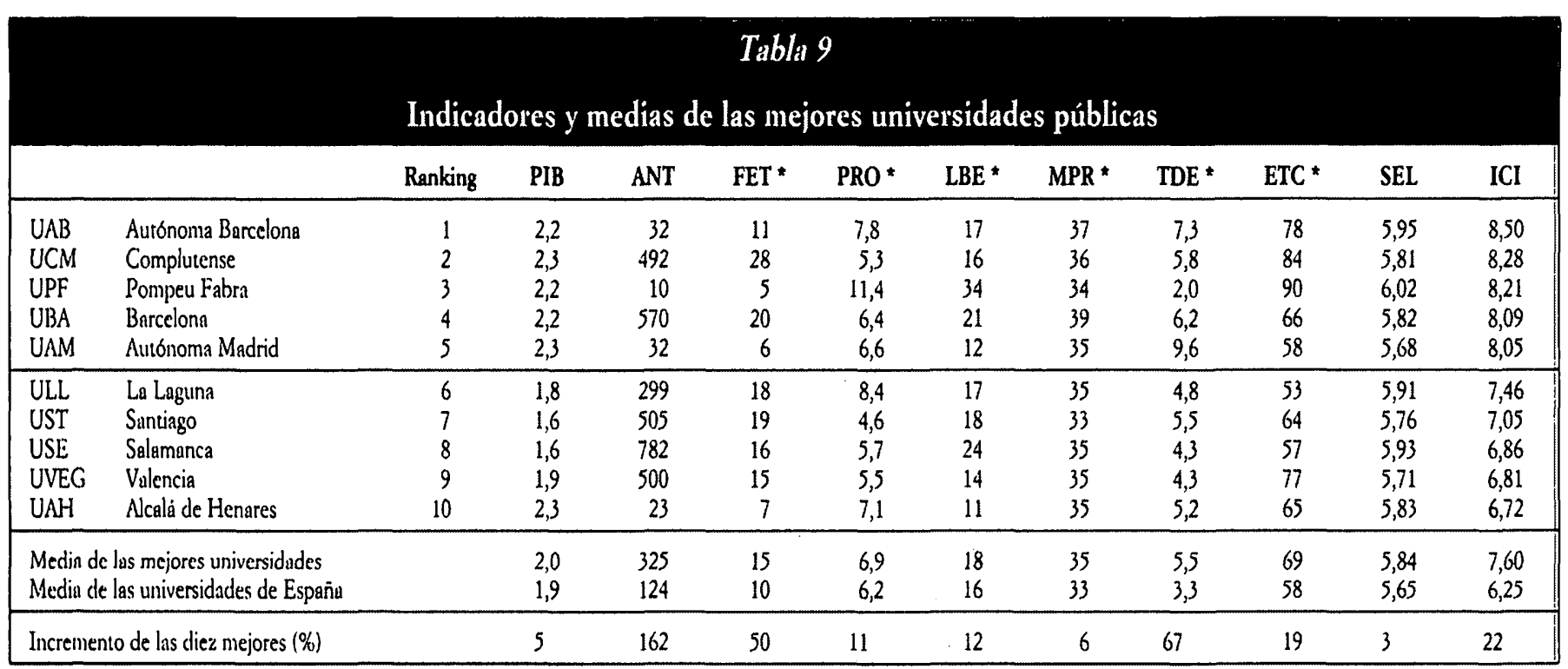

Fuentes: Tablas 1, 3 y 5 .

hemos calculado casi un centenar de indicadores para todas las universidades españolas, utilizando índices y tasas sobre los datos oficiales publicados por el Estado. Nuestra propuesta aque de cinco indices de calidad es dabatible. La experiencia de otros países avanzados es que el análisis de la excelencia debe realizarse sucesivamente, por aproximación, a partir de la discusión científica y corrección de los índices anteriores. La medición de la calidad se va ajustando poco a poco, basándose en datos precisos y no en ideologías personales. Tras finalizar el estudio de las diversas universidades españolas, nuestro equipo de investigación está actualmente realizando el primer análisis comparativo serio de la calidad universitaria de España respecto del resto de los países del mundo. Utilizamos para ello los bancos de datos de la Unesco y de la OCDE en París. Consideramos que la calidad debe medirse tanto a nivel intra (dentro del país), como a nivel inter (comparativa con otros países) ${ }^{6}$. La Sociología se demuestra como un área de conocimiento utilísima para establecer pautas e índices de calidad universitaria. Nosotros hemos realizado la primera aproximación que se publica sobre el caso español. Esperamos que ahora otros científicos/as señalen deficiencias, propongan correcciones al centenar de indicadores y a los cinco índices, estimulando así una investigación adecuada sobre la excelencia universitaria ${ }^{7}$.
Georgetown University y Universitat de Barcelona.

1 «Misión de la Universidad» se refiere a la conferencia de OrTeGa en el Paraninfo de San Bernardo, en la Universidad de Madrid, en 1930. Se publica en José Ortegn y GASSET, Misión de la Universidad y otros ensayos afines (Madrid: Revista de Occidente, 1930).

2 Por cjemplo, la Facultad de Ciencias Económicas y Empresariales de la Uni. vcrsidad de Barcelona incluye entre otras las licenciaturas de Económicas, Administración y Dirección de Empresas, Investigación y Técnicas de Mercado, Sociología, una buena parte de la docencia de Ciencias Políticas y de la Administración, la diplomatura de Estadística, etc. El modelo es cada vez más el de la London School of Economics con numerosos programas de doctorado y de master diferentes, abarcando las ciencias sociales.

3 Son concretamente 77.021.323 d6lares (Association of Research Libraries, 2000: A23). A esto hay que añadir que los salarios de los catedráticos son también altos en esas universidades. Por ejemplo, en las treinta primeras universidades investigadoras la media del salario de un catedrático supera los 20 millones de pesetas al año. En el caso de Harvard University, por ejemplo, la media de los catedráticos es 25 millones. En esta media no se incluyen los catedráticos de la Facultad de Medicina que cobran bastante más.

${ }^{4}$ Más información detallada de las universidades norteamericanas se puede conseguir a través de la red en http://www.arl.org.

"Recuérdese que hay solamente diez universidades privadas.

${ }^{6}$ Véase el libro de Jordi Cais, Metodología del análisis comparativo (Madrid: Centro de Investigaciones Sociológicas, 1997), 201 pp. Es el número 21 de la colección Cuadernos Metodológicos.

${ }^{7}$ Los tres autores, del Departamento de Sociología y Análisis de las Organizaciones, de la Universidad de Barcelona, agradecen muy especialmente a Raúl Tormos (Universidad Autónoma de Barcelona) quien colaboró activamente en cálculos, tablas, y discusión de ideas. A su vez, Xavier Escandell Tur (University of Illinois, Urbana-Champaign) ayudó en los cálculos originales realizados hace un lustro. El catedrático Julio Iglesias de Ussel, entences decano de la Facultad de Ciencias Políticas y Sociología de la Universidad de Granada (actualmente Secretario de Estado de Educación y Universidades), impulsó esta investigación y su presentación pública en Granada. El catedrático de Bioquímica de la Uni- 
versidad de La Laguna - Enrique Meléndez Hevia - fue una fuente de inspiración. Algunas ideas se discutieron finalmente con Andreu Mas-Colell. El director de esta revista, catedrático Carlos Alba Tercedor, de la Universidad Autónoma de Madrid (mucho antes de que supiéramos que el artículo se iba a publicar en esta revista) contribuyó con ideas, críticas, y documentación de todo tipo. Fue además una compañía intelectual valiosísima en Georgetown University, donde se terminó de redactar el estudio. En esa universidad los dos «Sams» - Samuel Barnes, y Eusebio Mujal-León-fueron un constante acicate y ayuda. iDa gusto encontrar extranjeros que estiman tanto a España! La investigación original fue financiada por el Ministerio de Educación, Cultura y Deporte así como por la Cátedra Príncipe de Asturias de Georgetown University. Gracias pues a S. A. R. el Príncipe Felipe de Borbón, y a Endesa, por su apoyo e interés en la mejora del sistema universitario español. Hay otras personas bondadosas que nos han ayudado durante estos años; ellos/as ya saben quien son; nuestras mejores gracias.

Cualquier sugerencia sobre el estudio es bienvenida: demiguel@eco.ub.es. 